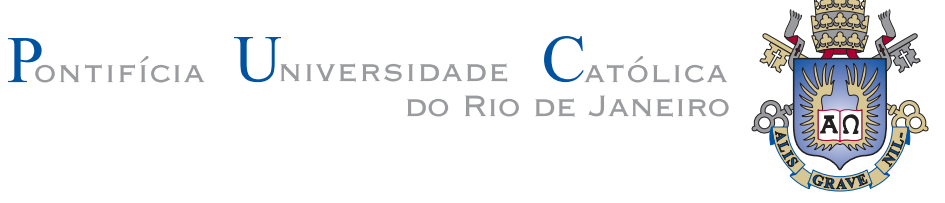

José Luis Calpa Juajinoy

Detecção desacoplada de sinais no enlace reverso de sistemas MU-MIMO com modulação espacial

Dissertação de Mestrado

Dissertação apresentada como requisito parcial para obtenção do grau de Mestre pelo Programa de Pós-graduação em Engenharia Elétrica do Departamento de Engenharia Elétrica do Centro Técnico Científico da PUC-Rio.

Orientador : Prof. Raimundo Sampaio Neto Coorientador: Dr. João Alfredo Cal Braz 


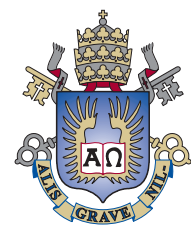

José Luis Calpa Juajinoy

\title{
Detecção desacoplada de sinais no enlace reverso de sistemas MU-MIMO com modulação espacial
}

\begin{abstract}
Dissertação apresentada como requisito parcial para obtenção do grau de Mestre pelo Programa de Pós-graduação em Engenharia Elétrica do Departamento de Engenharia Elétrica do Centro Técnico Científico da PUC-Rio. Aprovada pela Comissão Examinadora abaixo assinada.
\end{abstract}

Prof. Raimundo Sampaio Neto

Orientador

Centro de Estudos em Telecomunicações - PUC-Rio

\author{
Dr. João Alfredo Cal Braz \\ Coorientador \\ Instituto Nacional de Metrologia, Qualidade e Tecnologia - \\ INMETRO
}

Dr. Rodrigo Pereira David

Instituto Nacional de Metrología, Qualidade e Tecnología -

INMETRO

Dr. José Mauro Pedro Fortes

Centro de Estudos em Telecomunicações - PUC-Rio

Prof. Marcio da Silveira Carvalho

Coordenador Setorial do Centro Técnico Científico - PUC-Rio 
Todos os direitos reservados. É proibida a reprodução total ou parcial do trabalho sem autorização da universidade, do autor e do orientador.

José Luis Calpa Juajinoy

Graduou-se em Engenharia Eletrônica pela Universidade de Nariño (Pasto, Colômbia) em 2013.

Ficha Catalográfica

Calpa Juajinoy, José Luis

Detecção desacoplada de sinais no enlace reverso de sistemas MU-MIMO com modulação espacial / José Luis Calpa Juajinoy; orientador: Raimundo Sampaio Neto; coorientador: João Alfredo Cal Braz. - 2017.

$71 \mathrm{f}$. : il. color.; $30 \mathrm{~cm}$

Dissertação (mestrado) - Pontifícia Universidade Católica do Rio de Janeiro, Departamento de Engenharia Elétrica.

Inclui bibliografia.

1. Engenharia Elétrica - Tese. 2. Sistemas MIMO;. 3. Enlace reverso;. 4. Modulação espacial;. 5. Desacoplamento de sinais;. 6. Detecção. I. Sampaio Neto, Raimundo. II. Cal-Braz, João Alfredo. III. Pontifícia Universidade Católica do Rio de Janeiro. Departamento de Engenharia Elétrica. IV. Título. 


\section{Agradecimentos}

Toda ação ou atividade na vida de qualquer pessoa deve ser feita com a bênção de Deus para que seja bem sucedida. É por isso que agradeço a Deus e à Virgem de Guadalupe pela oportunidade de realizar o sonho de estudar num país tão maravilhoso como é o Brasil.

À CAPES e à PUC-Rio, pelos auxílios concedidos, sem os quais este trabalho não poderia ser realizado.

A meu orientador Raimundo Sampaio Neto e a meu co-orientador João Alfredo Cal Braz por toda a ajuda, pelo apoio e as sugestões feitas para que o trabalho realizado nesta dissertação fosse feito da melhor maneira.

A meus pais Juan Bosco e Marleny por serem minha principal motivação, por serem o exemplo de trabalho e amor, pela minha vida, tudo que eu sou eu devo a eles.

A meus irmãos Juan Francisco, Oscar Mauricio, David Sebastián e minhas irmãs Andrea Milena e Gabriela Sofía pelo apoio, pelo amor e carinho de sempre.

A minha namorada Diana Figueroa por ser minha companhia nos momentos mais difíceis, por ser minha luz em tempos de escuridão.

A Juanita, Salomé e Nicolás pelos sorrisos e pela sua existência.

A meus colegas do Cetuc, Juan Pablo, Azucena, Catherine, Jennifer, Alberth, Mauricio, Junior, Américo, Christian, Javier pela companhia e pelos momentos compartilhados na PUC.

A Leonel Arévalo e Rodrigo Pereira David pela colaboração na preparação desta dissertação.

A meus familiares, amigos e amigas por serem parte da minha vida. 


\section{Resumo}

Calpa Juajinoy, José Luis; Sampaio Neto, Raimundo (Orientador); Cal-Braz, João Alfredo (Co-orientador). Detecção desacoplada de sinais no enlace reverso de sistemas MU-MIMO com modulação espacial. Rio de Janeiro, 2017. 71p. Dissertação de Mestrado - Departamento de Engenharia Elétrica, Pontifícia Universidade Católica do Rio de Janeiro.

Este trabalho de dissertação de mestrado apresenta os resultados obtidos com a conjunção de duas técnicas propostas para utilização em modernos sistemas de comunicações: a Modulação Espacial (Spatial Modulation - SM) e a detecção desacoplada de sinais. Na primeira parte são abordados os fundamentos teóricos da deteç̧ão de sinais com modulação espacial, uma comparação entre os sistemas MIMO (Multiple Input Multiple Output) tradicionais e os sistemas SM-MIMO, uma revisão bibliográfica sobre trabalhos previamente feitos no tema e os diferentes tipos de detectores que podem ser empregados em sistemas com modulação espacial. A seguir são abordadas diferentes técnicas para desacoplamento de sinais, as quais permitem a separação na estação radio-base dos sinais oriundos de diferentes tipos de usuários, visando simplificar e adequar o procedimento de detecção às necessidades do usuário da rede. Finalmente uma análise de desempenho, em termos da taxa de erro de bit, e complexidade computacional, em termos do número médio de flops requerido por vetor de símbolos detectado, é realizada para as diferentes associações de técnicas de desacoplamento e detectores SM enfocados neste trabalho.

\section{Palavras-chave}

Sistemas MIMO; Enlace reverso; Modulação espacial; Desacoplamento de sinais; Detecção 


\section{Abstract}

Calpa Juajinoy, José Luis; Sampaio Neto, Raimundo (Advisor); Cal-Braz, João Alfredo (Co-advisor). Decoupled signal detection in the up-link of MU-MIMO systems with spatial modulation. Rio de Janeiro, 2017. 71p. Dissertação de Mestrado - Departamento de Engenharia Elétrica, Pontifícia Universidade Católica do Rio de Janeiro.

This work dissertation presents the results obtained from the conjunction of two proposal techniques for the use in modern systems of communications: the Spatial Modulation and the Decoupling Signal Detection. In the first part are discussed the theorical bases of the signal detection with Spatial Modulation, a comparison between the traditional MIMO systems and the SM-MIMO systems, a bibliographical review about previous works in the topic and the different kinds of detectors that can be used in systems with Spatial Modulation. Then the different techniques of signal decoupling are discussed, which allow the separation in the radio base station of the signals coming from the different classes of users, to simplify and adapt the process of detection and the requirements of the user in the network. Finally a performance analysis in terms of the bit error rate and computational complexity in terms of average number of flops required fot the vector of symbols detected, is done for the studied detectors in the dissertation, using the same different techniques of decoupling studied in this work.

\section{Keywords}

MIMO systems; Up-link; Spatial Modulation; Signal decoupling; Detection 


\section{Sumário}

1 Introdução 14

$\begin{array}{lll}1.1 & \text { Organização da Dissertação } & 16\end{array}$

2 Detecção de sinais com modulação espacial $\quad 18$

2.1 Modulação espacial generalizada - GSM 18

2.2 MIMO Massivo vs GSM-MIMO 22

2.3 Técnicas de detecção $\quad 23$

2.3.1 Detector ótimo Maximum Likelihood - ML 23

2.3.2 Detector Project Based List - PBL 24

3 Técnicas de desacoplamento de sinais em enlace reverso para sistemas SM-MIMO

3.1 Topologia do sistema MIMO GSM multiusuário e modelo de sinal do enlace reverso

3.2 Detecção desacoplada de sinais - DSD 32

3.3 Decomposição em valores singulares - SVD 36

3.4 Desacoplamento Zero Forcing-Maximum Likelihood (ZF-ML) 36

4 Avaliação de desempenho e complexidade $\quad \mathbf{4 0}$

4.14 Usuários 41

4.1.1 4 Classes de 1 usuário: 42

4.1.2 2 Classes de 2 usuários: $\quad 45$

4.1.3 Efeitos de propagação e correlação 48

4.1.3.1 Correlação na transmissão 49

4.1.3.2 Correlação na transmissão e na recepção 55

4.216 Usuários $\quad 61$

4.33 Usuários 63

5 Conclusões $\quad 64$

$\begin{array}{ll}\text { Referência bibliográfica } & 67\end{array}$

A Equivalência entre os receptores ZF-ML e SVD-ML 69 


\section{Lista de figuras}

2.1 Diagrama de blocos sistema MIMO com modulação espacial. $\quad 19$

2.2 Modelo passa-baixa discreto de um Sistema MIMO. 21

3.1 Modelo de rede sem fio. 30

4.1 Cenário de simulação 40

4.2 Desempenho dos detectores ML, Project Based List e Project Based List com redução de reticulado para 4 usuários com modulação espacial $\left(N_{t_{n}}=4, N_{a}=2, N_{r}=16\right)$.

4.3 Complexidade computacional dos detectores ML, Project Based List e Project Based List com redução de reticulado para 4 usuários com modulação espacial $\left(N_{t_{n}}=4, N_{a}=2, N_{r}=16\right)$.

4.4 Cenário de desacoplamento: 4 classes - 1 usuário por classe.

4.5 Comparação de desempenho das técnicas de desacoplamento estudadas para 4 classes de 1 usuário por classe $\left(N_{t_{n}}=4, N_{a}=2\right.$, $\left.N_{r}=16\right)$.

4.6 Comparação em termos de complexidade computacional das técnicas de desacoplamento estudadas para 4 classes de 1 usuário por classe $\left(N_{t_{n}}=4, N_{a}=2, N_{r}=16\right)$.

4.7 Cenário de desacoplamento: 2 classes - 2 usuário por classe.

4.8 Comparação de desempenho das técnicas de desacoplamento estudadas para 2 classes com 2 usuários por classe $\left(N_{t_{n}}=4, N_{a}=2\right.$, $\left.N_{r}=16\right)$.

4.9 Comparação en termos de complexidade computacional das técnicas de desacoplamento estudadas para 2 classes de 2 usuário por classe $\left(N_{t_{n}}=4, N_{a}=2, N_{r}=16\right)$.

4.10 Desempenho das técnicas de desacoplamento para 4 classes de 1 usuário com efeitos de propagação e de correlação só na transmissão para um coeficiente $\rho=0,2\left(N_{t_{n}}=4, N_{a}=2, N_{r}=16\right)$.

4.11 Desempenho das técnicas de desacoplamento para 4 classes de 1 usuário com efeitos de propagação e de correlação só na transmissão para um coeficiente $\rho=0,4\left(N_{t_{n}}=4, N_{a}=2, N_{r}=16\right)$.

4.12 Desempenho das técnicas de desacoplamento para 4 classes de 1 usuário com efeitos de propagação e de correlação só na transmissão para um coeficiente $\rho=0,6\left(N_{t_{n}}=4, N_{a}=2, N_{r}=16\right)$.

4.13 Desempenho das técnicas de desacoplamento para 4 classes de 1 usuário com efeitos de propagação e de correlação só na transmissão para um coeficiente $\rho=0,8\left(N_{t_{n}}=4, N_{a}=2, N_{r}=16\right)$.

4.14 Desempenho das técnicas de desacoplamento para 2 classes de 2 usuários com efeitos de propagação e de correlação só na transmissão para um coeficiente $\rho=0,2\left(N_{2} t_{n}=4, N_{a}=2\right.$, $\left.N_{r}=16\right)$. 
4.15 Desempenho das técnicas de desacoplamento para 2 classes de 2 usuários com efeitos de propagação e de correlação só na transmissão para um coeficiente $\rho=0,4\left(N_{t_{n}}=4, N_{a}=2\right.$, $\left.N_{r}=16\right)$.

4.16 Desempenho das técnicas de desacoplamento para 2 classes de 2 usuários com efeitos de propagação e de correlação só na transmissão para um coeficiente $\rho=0,6\left(N_{t_{n}}=4, N_{a}=2\right.$, $\left.N_{r}=16\right)$.

4.17 Desempenho das técnicas de desacoplamento para 2 classes de 2 usuários com efeitos de propagação e de correlação só na transmissão para um coeficiente $\rho=0,8\left(N_{t_{n}}=4, N_{a}=2\right.$, $\left.N_{r}=16\right)$.

4.18 Desempenho das técnicas de desacoplamento para 4 classes de 1 usuário com efeitos de propagação e de correlação na transmissão e na recepção para um coeficiente $\rho=0,2\left(N_{t_{n}}=4, N_{a}=2\right.$, $\left.N_{r}=16\right)$.

4.19 Desempenho das técnicas de desacoplamento para 4 classes de 1 usuário com efeitos de propagação e de correlação na transmissão e na recepção para um coeficiente $\rho=0,4\left(N_{t_{n}}=4, N_{a}=2\right.$, $\left.N_{r}=16\right)$.

4.20 Desempenho das técnicas de desacoplamento para 4 classes de 1 usuário com efeitos de propagação e de correlação na transmissão e na recepção para um coeficiente $\rho=0,6\left(N_{t_{n}}=4, N_{a}=2\right.$, $\left.N_{r}=16\right)$.

4.21 Desempenho das técnicas de desacoplamento para 4 classes de 1 usuário com efeitos de propagação e de correlação na transmissão e na recepção para um coeficiente $\rho=0,8\left(N_{t_{n}}=4, N_{a}=2\right.$, $\left.N_{r}=16\right)$.

4.22 Desempenho das técnicas de desacoplamento para 2 classes de 2 usuários com efeitos de propagação e de correlação na transmissão e na recepção para um coeficiente $\rho=0,2\left(N_{t_{n}}=4, N_{a}=2\right.$, $\left.N_{r}=16\right)$.

4.23 Desempenho das técnicas de desacoplamento para 2 classes de 2 usuários com efeitos de propagação e de correlação na transmissão e na recepção para um coeficiente $\rho=0,4\left(N_{t_{n}}=4, N_{a}=2\right.$, $\left.N_{r}=16\right)$.

4.24 Desempenho das técnicas de desacoplamento para 2 classes de 2 usuários com efeitos de propagação e de correlação na transmissão e na recepção para um coeficiente $\rho=0,6\left(N_{t_{n}}=4, N_{a}=2\right.$, $\left.N_{r}=16\right)$.

4.25 Desempenho das técnicas de desacoplamento para 2 classes de 2 usuários com efeitos de propagação e de correlação na transmissão e na recepção para um coeficiente $\rho=0,8\left(N_{t_{n}}=4, N_{a}=2\right.$, $\left.N_{r}=16\right)$.

4.26 Desempenho das técnicas de desacoplamento para 16 classes de 1 usuário $\left(N_{t_{n}}=4, N_{a}=2, N_{t}=N_{r}=64\right)$.

4.27 Complexidade computacional das técnicas de desacoplamento para 16 classes de 1 usuário. 
4.28 Desempenho das técnicas de desacoplamento para 3 classes de 1 usuário $\left(N_{t_{n}}=4, N_{a}=2, N_{t}=12, N_{r}=16\right)$. 


\section{Lista de tabelas}

2.1 Exemplo de tabela de mapeamento 


\section{Lista de símbolos e abreviações}

$\begin{array}{ll}\text { BER } & \text { Bit Error Rate } \\ \text { DSD } & \text { Decoupling Signal Detection } \\ \text { ERB } & \text { Estação Rádio Base } \\ \text { GSM } & \text { Generalized Spatial Modulation } \\ \text { LR } & \text { Lattice Reduction } \\ \text { MIMO } & \text { Multiple Input Multiple Output } \\ \text { ML } & \text { Maximum Likelihood } \\ \text { MU } & \text { Multi User } \\ \text { PBL } & \text { Project Based List } \\ \text { QPSK } & \text { Quadrature Phase Shif Keying } \\ \text { RF } & \text { Radio Frequência } \\ \text { SM } & \text { Spatial Modulation } \\ \text { SVD } & \text { Singular Values Descomposition } \\ \text { SNR } & \text { Signal Noise Relation } \\ \text { ZF } & \text { Zero Forcing }\end{array}$


Tem todo o tempo Ítaca na mente. Estás predestinado a ali chegar. Mas não apresses a viagem nunca. Melhor muitos anos levares de jornada e fundeares na ilha velho enfim, rico de quanto ganhaste no caminho, sem esperar riquezas que Itaca te desse. Uma bela viagem deu-te Ítaca. Sem ela não te ponhas a caminho. Mais do que isso não the cumpre dar-te.

Ítaca não te iludiu, se a achas pobre. Tu te tornaste sábio, um homem de experiência, e agora sabes o que significam Ítacas.

Constantino Cavafis, Ítaca. 


\section{Introdução}

A principal característica dos seres humanos é a capacidade de se comunicar. A comunicação permite às pessoas manifestar as necessidades, desejos, emoções e informação que pode ser útil ou importante para outras pessoas. A comunicação permite também o trabalho em equipe permitindo alcançar objetivos que seriam impossíveis de serem obtidos trabalhando sozinho. Neste sentido a tecnologia, e mais especificamente os sistemas de telecomunicações, têm desempenhado um papel importante no mundo globalizado da atualidade, em áreas como educação, negócios, ciência, saúde, transporte, permitindo a interação e o acesso à informação de uma maneira mais rápida e fácil e em qualquer lugar e momento. A história dos sistemas de telecomunicações começou em 1830 com a aparição do telégrafo. Muitos anos depois foi impulsionada pela chegada do telefone criado por Alexander Graham Bell em 1876. Anos depois o trabalho desenvolvido por Heinrich Hertz e James Maxwell permitiu a transmissão do primeiro sinal electromagnético, criando assim o primeiro sistema de antenas. Em 1892 o inventor $\mathrm{Ni}$ kola Tesla sugeriu a transmissão de sinais de um ponto a outro e em 1894 o italiano Guglielmo Marconi construiu o primeiro telégrafo sem fio introduzindo o conceito de radio transmissão. Algumas décadas depois, em 1936 o britânico Alan Turing descreveu o conceito geral da computação moderna que permitiu em 1979 a criação do primeiro sistema celular analógico. Nas décadas de 80 e 90 a implementação de redes celulares e o nascimento da Internet permitiram a chegada dos dispositivos inteligentes, "smart-devices", que na atualidade são frequentes em todas as atividades das pessoas. Um dispositivo inteligente é um dispositivo eletrônico que pode ser conectado a outros dispositivos ou redes utilizando diferentes protocolos de comunicação. Na atualidade o número de dispositivos é imenso, e a demanda para a utilização de todos os recursos que oferecem vai continuar crescendo. Assim o estudo de alternativas para aumentar as taxas de dados, reduzir a latência e o consumo de energia e diminuir os custos computacionais para o processamento dos sinais é uma necessidade nos sistemas de telecomunicações modernos.

Uma das alternativas propostas foi a implementação de sistemas 
MIMO (Multiple Input - Multiple Output). Durante os últimos anos a tecnologia MIMO tem sido muito importante nas comunicações sem fio, já que permite o aumento da taxa de transferência da informação e a redução da taxa de erro. Isto é conseguido com a utilização de diferentes canais na transmissão de dados ou a multiplexação espacial, efeito gerado pelo espaçamento físico das antenas. MIMO é uma parte importante da maioria dos modernos padrões de comunicação sem fio. Infelizmente os sistemas MIMO também apresentam alguns desafios que devem ser encarados. Em sistemas MIMO mono usuários (SU-MIMO) é muito comum que os sinais sofram distorção pelo ruído dos canais e pela interferência entre as múltiplas antenas. No entanto em sistemas MIMO multiusuários (MU-MIMO) além das distorções apresentadas em SU-MIMO tem-se também a interferência entre os múltiplos usuários. Tais perturbações fazem com que a detecção eficiente dos sinais no enlace reverso do sistema requeira uma elevada complexidade computacional. Neste sentido o processamento eficiente dos sinais recebidos é um aspecto fundamental para que sistemas MIMO sejam viáveis. Nas comunicações de próxima geração, como as redes celulares de quinta geração (5G), determinados aspectos aparecem entre seus maiores desafios [1], [2]: obtenção de eficiência espectral elevada, conectividade massiva de dispositivos e redução de energia e custos com as operadoras e com os dispositivos que requerem longa vida de bateria. O primeiro desafio será endereçado por um conjunto de tecnologias, inclusive o uso de sistemas com múltiplas antenas. $\mathrm{O}$ suporte a conectividade massiva se dará pela implementação de sistemas massivos, como os sistemas MIMO massivos e formas eficientes de atender aos diferentes requerimentos destes usuários. Por fim, a redução dos custos poderá se dar por estratégias implantadas na camada física que permitam a redução da energia e dos dispositivos eletrônicos associados aos complexos sistemas de transmissão/recepção.

O trabalho desenvolvido nesta dissertação enfoca uma alternativa para simplificar o processamento dos sinais recebidos na estação radio base de sistemas com Modulação Espacial Generalizada, combinando técnicas de desacoplamento com técnicas eficientes para detecção de sinais em tais sistemas.

A Modulação Espacial Generalizada apresenta um método alternativo de transmissão de dados comparado aos sistemas MIMO com multiplexação espacial que confere a redução da energia gasta nos circuitos que compõem o transmissor. Nele, um subconjunto das antenas transmissoras é ativado a cada transmissão, resultando na necessidade de instalação de menos cadeias de radiofrequência ligadas às antenas transmissoras. Ao selecionar um grupo de antenas para realizar a transmissão, que por sua vez será detectado 
no lado receptor, caracteriza-se a posição das antenas transmissoras ativas, representadas pelos seus índices, como elementos portadores de informação, além dos símbolos oriundos da modulação digital empregada, emitidos pelas antenas.

Por outro lado o desacoplamento de sinais consiste na separação da informação recebida na ERB de acordo com os requerimentos dos diversos usuários. Isto é importante já que na próxima geração de comunicações sem fio as ERBs vão receber sinais de um número muito grande de dispositivos inteligentes, como por exemplo equipamentos meteorológicos, sensores, dispositivos de monitoramento do meio ambiente, saúde, segurança, celulares, tablets, etc. Ao considerarmos um sistema em que uma estação base (ERB) comunica-se com diversos usuários, é conveniente que, no enlace reverso, o sinal recebido na ERB possa ser separado por usuário, ou, mais especificamente, por grupos de usuários que possuam requerimentos semelhantes de confiabilidade, latência, etc. Desta forma, o detector pode empregar estratégias de detecção adequadas. Nesta dissertação são avaliadas as vantagens e desvantagens da utilização de maneira conjunta das técnicas referidas anteriormente na detecção de sinais no enlace reverso de sistemas MIMO.

A proposta desta dissertação alinha-se com os futuros desenvolvimentos das comunicações sem fio, pois apresenta métodos de atendimento aos múltiplos usuários que demandam conectividade da ERB, atendendo com base nos métodos de desacoplamento e detecção, aos seus requerimentos específicos de desempenho. Adicionalmente, fornece meios de redução dos custos com os dispositivos dos sistemas transmissores, pela redução do número de cadeias de RF.

\subsection{Organização da Dissertação}

O trabalho desenvolvido nesta dissertação está dividido em três capítulos, da seguinte maneira:

- No Capítulo 2 são apresentados os conceitos básicos da detecção de sinais com modulação espacial. Na primeira seção do capítulo a modulação espacial generalizada -GSM é apresentada, seguida de uma comparação entre MIMO Massivo e GSM-MIMO e finalmente são abordadas as técnicas de detecção que serão utilizadas na dissertação, os detectores ótimo ML e Project Based List.

- No Capítulo 3 são abordadas as técnicas de desacoplamento de sinais em enlace reverso para sistemas SM-MIMO. Na primeira seção do capítulo a topologia e o modelo de sinal são apresentados. Nas seguintes 
seções são apresentadas as diferentes técnicas de desacoplamento, tais como o desacoplamento DSD, SVD e Zero Forcing-ML.

- No Capítulo 4 é apresentada a avaliação em termos de desempenho e complexidade da utilização conjunta da modulação espacial e a detecção desacoplada de sinais. A avaliação incluiu também os efeitos propagação e correlação entre antenas no modelo de sinal.

- No capítulo 5 as conclusões da dissertação são resumidas e tópicos propostos para futuros estudos são abordados. 


\section{2}

\section{Detecção de sinais com modulação espacial}

Os sistemas de comunicações Multiple Input - Multiple Output (MIMO) convencionais têm como objetivo aproveitar os ganhos de arranjo, diversidade e multiplexação. $\mathrm{O}$ ganho de multiplexação espacial, é relacionado à possibilidade das "streams" de dados poderem ser transmitidos em paralelo através do mesmo canal, o que permite um aumento da capacidade de canal e taxas de transmissão maiores.

A modulação espacial (SM) é uma proposta de comunicação com múltiplas antenas que tem vantagens sobre os sistemas MIMO convencionais, como por exemplo a redução na utilização dos recursos de rádio do sistema e a melhora em termos da eficiência energética, as quais são obtidas pela redução do número de cadeias de transmissão de radio frequências [3].

Este capítulo primeiramente aborda os fundamentos teóricos necessários para a compreensão da técnica, depois na Seção 2.2 é feita uma comparação entre os sistemas MIMO e SM-MIMO e uma revisão bibliográfica sobre alguns trabalhos previamente feitos no tema, e finalmente, na Seção 2.3 estuda-se diferentes tipos de detectores que podem ser empregados em sistemas SM-MIMO.

\subsection{Modulação espacial generalizada - GSM}

A modulação espacial é uma técnica proposta para sistemas MIMO, a qual é capaz de superar o desempenho de muitos esquemas de transmissão MIMO convencionais em termos da taxa de erro de bit, com menor custo e complexidade computacional. Exemplos são apresentados em [4] onde o sistema SM é comparado com sistema V-BLAST e Alamouti e [5] onde o sistema GSM é comparado com V-BLAST, Alamouti e SM. O conceito básico de SM estabelece que só um subconjunto das antenas transmissoras é ativado para a transmissão de símbolos e que o fluxo de dados transmitido controla diretamente as antenas a serem ativadas. A operação é executada por duas unidades independentes para a alocação de informação: (a) uma primeira unidade encarregada dos símbolos da modulação empregada na transmissão (b) uma segunda unidade encarregada da seleção da combinação de antenas que será ativada dentro de um conjunto de combinações válidas para 
a transmissão.

Na Figura 2.1 é apresentado o diagrama de blocos de um sistema MIMO com modulação espacial.
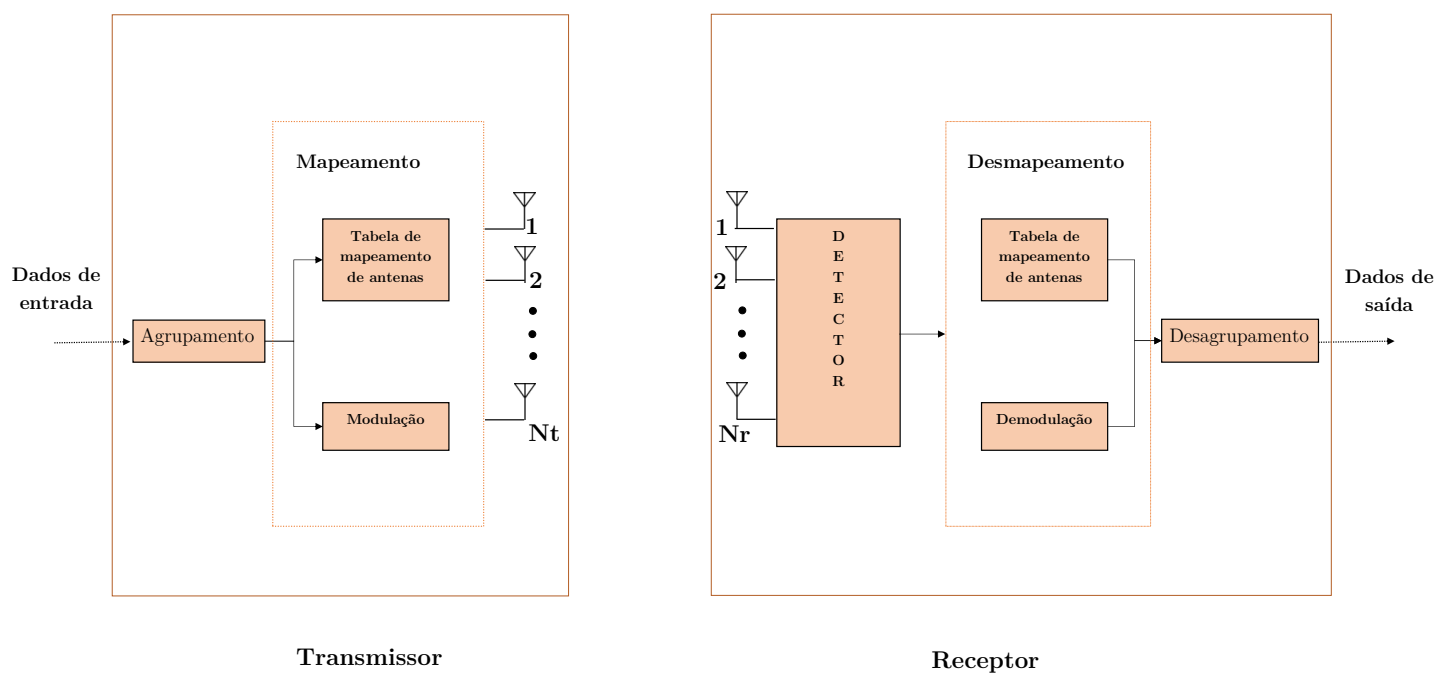

Figura 2.1: Diagrama de blocos sistema MIMO com modulação espacial.

Conforme apresentado, o transmissor primeiramente separa o fluxo de dados binário e forma blocos de igual tamanho. $\mathrm{O}$ tamanho dos blocos é igual ao número de bits transmitidos em um uso do canal pelo sistema. A taxa de transmissão $R$ atingida por um sistema MIMO com GSM é dada por:

$$
R=\log _{2}\left(N_{c}\right)+N_{a} \log _{2}(M)
$$

Na expressão $N_{c}$ representa o número de combinações válidas de antenas, $N_{a}$ é o número de antenas simultaneamente ativas no transmissor e $M$ é a ordem da modulação digital empregada. A escolha de $N_{c}$ é um aspecto muito importante e determinante na definição da taxa de transmissão. É por isso que uma restrição importante é que $N_{c}$ seja potência de dois a fim de que $\log _{2}\left(N_{c}\right) \in \mathbb{N}$ e assim cada combinação possa ser mapeada em um código binário inteiro. Dado o objetivo de maximizar a taxa de dados, é necessário utilizar o maior número de combinações de antenas possíveis. O número de combinações é determinado da seguinte maneira:

$$
N_{c}=\left\lfloor\left(\begin{array}{c}
N_{t} \\
N_{a}
\end{array}\right)\right\rfloor_{2^{p}},
$$


O termo $\lfloor x\rfloor_{2^{p}}$ representa a maior potência de 2 que é menor ou igual a $x$. Por exemplo tem-se um sistema SM com $N_{t}=4$ e $N_{a}=2$, neste caso um exemplo de mapeamento de combinações permitidas, é apresentado na matriz $\mathbf{V}^{\left(N_{t}, N_{a}\right)}$, de dimensão $N_{t} \times N_{c}$, é:

$$
\mathbf{V}^{(4,2)}=\left[\begin{array}{llll}
1 & 1 & 0 & 0 \\
1 & 0 & 1 & 0 \\
0 & 1 & 0 & 1 \\
0 & 0 & 1 & 1
\end{array}\right] \text {. }
$$

No total são gerados $N_{a}$ símbolos $b_{i} ; i=1,2, \ldots, N_{a}$, onde $N_{a}$ corresponde ao número de moduladores empregados pelas $N_{a}$ antenas na transmissão. Os símbolos fazem parte da constelação $\mathcal{S}$ empregada, têm energia média $\mathbb{E}\left[\left|b_{i}\right|^{2}\right]=E_{s}$, são representados pelo conjunto $\mathbb{B}$ e mapeiam os $N_{a} \log _{2}(M)$ bits do bloco transmitido [6]. Os símbolos são arranjados no vetor b de dimensão $N_{a} \times 1$, de forma que $\mathbf{b} \in \mathbb{B}^{N_{a}}$. O bloco de dados transmitidos é representado pelo vetor de transmissão s, formado com o uso das matrizes de posicionamento, estas matrizes têm como função alocar os elementos de $\mathbf{b}$ nas corretas posições de $\mathbf{s}$ de acordo com a combinação de antenas definidas no mapeamento. Um transmissor com $N_{c}$ combinações de antenas possui o mesmo número de matrizes de posicionamento $\mathbf{P}_{c}$ de dimensão $N_{t} \times N_{a}$, dadas por:

$$
\mathbf{P}_{c}=\mathbf{I}_{N_{t}}^{\left(\mathbf{v}_{c}\right)}, \quad c=1,2, \ldots, N_{c},
$$

onde $\mathbf{I}_{N_{t}}^{\left(\mathbf{v}_{c}\right)}$ é a matriz composta pelas colunas da matriz identidade $\mathbf{I}$ de dimensão $N_{t} \times N_{t}$ indexadas pelo vetor lógico $\mathbf{v}_{c}$. Assim, ao se considerar que para a transmissão de uma sequência binária foi empregada a combinação de antenas $c=k$, o bloco de dados transmitidos é dado pelo vetor com a forma:

$$
\mathbf{s}=\mathbf{P}_{k} \mathbf{b}
$$

Define-se assim, o conjunto $\mathcal{S}=\left\{\mathbf{P}_{c} \mathbf{b} \mid c \in\left\{1,2, \cdots, N_{C}\right\}, \mathbf{b} \in \mathbb{B}^{N_{a}}\right\}$, que reúne os possíveis valores de s. A título de exemplificação, a Tabela 2.1 exibe os mapeamentos realizados no transmissor para um sistema com esquema de modulação QPSK, $N_{t}=4, N_{a}=2$ e a matriz de combinações de antenas exibida em (2-3). 
Uma fácil visualização do ambiente MIMO é representado na Figura 2.2, que considera o equivalente passa-baixa discreto dos sinais transmitidos.
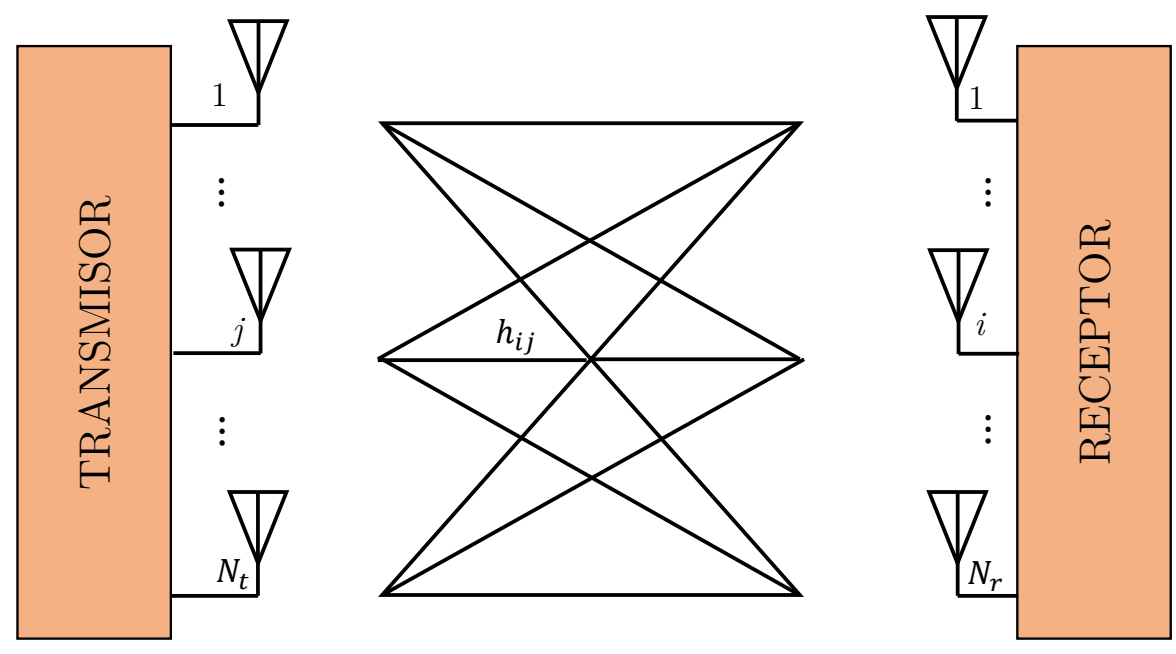

Figura 2.2: Modelo passa-baixa discreto de um Sistema MIMO.

$O$ vetor de símbolos da transmissão atravessa o canal MIMO e chega às antenas receptoras. O sinal recebido é uma combinação linear dos $N_{t}$ símbolos de entrada mais uma componente de ruído. Os canais entre as antenas de transmissão e as antenas de recepção, representa um coeficiente da matriz de canal H, os elementos de aquela matriz são em geral complexos, determinísticos ou aleatórios. Em notação vetorial o sinal recebido de dimensão $N_{r} \times 1$ tem a forma:

$$
\mathbf{y}=\mathbf{H s}+\mathbf{n},
$$

onde o vetor de ruido $\mathbf{n}$ é um vetor complexo gaussiano de média nula e matriz de autocorrelação $K_{n}=\left[\mathbf{n n}^{\mathcal{H}}\right]=\sigma^{2} \mathbf{I}$.

Considerando que a $k$-ésima combinação de antenas é empregada, a equação (2-6) pode ser reescrita assim:

$$
\mathbf{y}=\mathbf{H}_{k} \mathbf{b}+\mathbf{n}
$$

O termo $\mathbf{H}_{k}$ representa a matriz de canal que possui apenas as colunas referentes às antenas transmissoras ativas em cada uma das transmissões 
feitas, a dimensão da matriz é $N_{r} \times N_{a}$. Assim o papel dos receptores vai consistir na detecção das combinação escolhida na transmissão e do vetor de símbolos $\hat{b}$.

\subsection{MIMO Massivo vs GSM-MIMO}

$\mathrm{Na}$ atualidade os sistemas sem fio que utilizam um grande número de antenas na transmissão e recepção ou sistemas MIMO massivo tem-se convertido em uma das melhores alternativas para os sistemas de quinta geração (5G). As comunicações $5 \mathrm{G}$ terão que tratar com tecnologias que possam oferecer um maior incremento na capacidade da transmissão mas que não requeiram maior largura da banda nem consumo de energia. MIMO massivo permite alcançar os requerimentos na taxa de dados mas o consumo de energia e a complexidade computacional são fatores que precisam ser melhorados. Além disso o custo monetário dos sistemas MIMO Massivo é alto porque precisa de uma cadeia RF em cada um dos transmissores, fator que não acontece nos sistemas GSM-MIMO os quais são capazes de transmitir com muitas antenas mas empregam um número reduzido de cadeias de RF. GSM-MIMO oferece as vantagens da redução de hardware RF, complexidade computacional e custo [7].

Em [7] são propostos dois algoritmos de deteccão de GSM-MIMO em enlace reverso, os quais alcançam um desempenho muito bom. Uma comparação em UPLINK é feita e o resultado mostra que SM-MIMO melhora o desempenho de MIMO massivo.

Em [8] um novo esquema de precodificação é proposto para sistemas multiusuário com modulação espacial (MU-SM) para downlink. As simulações mostram que o esquema elimina a interferência multi-usuário permitindo fazer uma detecção ML ótima mais facilmente.

As referências citadas anteriormente mostram que o desempenho obtido pelos sistemas SM-MIMO é muito bom mas em termos da complexidade computacional na estação radio base (ERB) não apresenta uma melhora significativa, é necessário avaliar técnicas que permitam reduzir aquela complexidade, mantendo um bom desempenho tornando assim a SM muito mais viável e uma prioridade nos sistemas de comunicações 5G atuais. 


\subsection{Técnicas de detecção}

Nesta seção são descritas algumas técnicas de detecção de sinais que podem ser empregadas nos sistemas SM-MIMO e que serão avaliadas em termos do desempenho e complexidade no Capítulo 4. Será suposto o perfeito conhecimento de $\mathbf{H}$ pelo receptor.

\subsubsection{Detector ótimo Maximum Likelihood - ML}

O detector ótimo é baseado na seguinte expressão

$$
\hat{\mathbf{s}}_{M L}=\underset{\mathbf{s} \in \mathbb{B}^{N_{t}}}{\operatorname{argmin}}\|\mathbf{r}-\mathbf{H s}\|^{2}
$$

Considerando um sistema uplink com $N_{t}$ antenas transmissoras e $N_{r}$ antenas receptoras, $N_{t} \leq N_{r}$, onde $N_{t}$ representa o número de símbolos que são transmitidos simultaneamente. Seja $\mathbf{s} \in \mathbb{B}^{N_{t}}, \mathbf{s}=\left[s_{1}, s_{2}, \ldots, s_{N_{t}}\right]^{T}$ o vetor de símbolos transmitidos, onde $\mathbb{B}$ representa um conjunto finito complexo com cardinalidade $M$ e $\mathbf{s}_{i}$ é o sinal complexo com energia unitária $\left(\mathbb{E}\left[\left|\mathbf{s}_{i}\right|\right]=1\right)$ do $i$-ésimo usuário. A ideia é encontrar o vetor $\mathbf{s}$ cuja norma ao quadrado da diferença entre $\mathbf{r}$ que representa o vetor recebido e Hs que representa a mensagem hipótese corrompida pelo canal $\mathbf{H}$ seja mínima. O método apresenta o melhor desempenho em termos da taxa de erro de detecção mas a complexidade computacional é muito alta, e aumenta exponencialmente dependendo da ordem da modulação ou do número de antenas na transmissão. Isto é devido à necessidade de testar os $|\mathbb{B}|^{N_{t}}$ valores possíveis do vetor $\mathbf{s}$ para escolher aquele que satisfaz a métrica (2-8). A alta complexidade computacional é um argumento suficiente para desenvolver detectores sub-ótimos que permitam ter um desempenho perto ao obtido pelo ML.

Levando em consideração a estrutura do sinal GSM, o detector ML, pode ser reescrito assim [6]:

$$
\{\hat{k}, \hat{\mathbf{b}}\}_{M L}=\underset{\substack{\mathbf{b} \in \mathbb{B}^{N_{a}} \\ \mathbf{k} \in 1,2, \ldots, N_{c}}}{\arg \min }\left\|\mathbf{y}-\mathbf{H}_{k} \mathbf{b}\right\|^{2} .
$$

Finalmente, o vetor de símbolos GSM é reconstruído fazendo-se:

$$
\hat{\mathbf{s}}_{\mathrm{ML}}=\mathbf{P}_{\hat{k}} \hat{\mathbf{b}}
$$


O custo computacional do detector ML com modulação espacial é proporcional ao ordem da modulação, o número de antenas ativas na transmissão e ao número de combinações validas. Tem-se assim que o número de hipóteses a serem testadas no detector ML na Equação (2-9) é $N_{c} M^{N_{a}}$.

\subsubsection{Detector Project Based List - PBL}

Uma nova estratégia de detecção para sistemas MIMO que empregam modulação espacial é apresentada em [9]. O PBL é um detector multi-etapa que gera uma lista de candidatos do vetor de sinal recebido, os classifica pela menor distancia do vetor de dados aos subespaços vetoriais gerados pela matriz do canal para cada possível combinação de antenas transmissoras. As métricas de qualidade e da lista permitem a escolha do melhor candidato e da lista que será testada, respectivamente. $\mathrm{O}$ desempenho obtido para este detector é mais próximo ao desempenho do detector ML e tem-se uma redução em termos de complexidade computacional.

A estratégia é composta por três fases, as quais serão explicadas a seguir.

\section{Fase 1. Classificação das combinações de antena de transmissão}

A primeira fase considera que o vetor recebido tende a estar mais perto ao espaço gerado pela matriz de canal empregada na transmissão $\mathbf{H}_{k}$, e que pequenas projeções são observadas nos restantes $N_{c}-1$ subespaços gerados pelas demais matrizes de canal $\mathbf{H}_{i}, i=1,2, \ldots, N_{c}, i \neq k$. A primeira fase é composta de um banco de $\mathbf{N}_{c}$ filtros lineares. Cada filtro $\mathbf{W}_{i}$ é uma matriz que projeta ortogonalmente o vetor de entrada no subespaço gerado por $\mathbf{H}_{i}$, que é a matriz de canal de uma das possíveis combinações de antenas de transmissão. Assumindo $N_{r} \geq N_{a}$ o filtro $\mathbf{W}_{i}, i=1,2, \ldots, N_{c}$ é dado por:

$$
\mathbf{W}_{i}=\mathbf{H}_{i}\left(\mathbf{H}_{i}^{H} \mathbf{H}_{i}\right)^{-1} \mathbf{H}_{i}^{H}=\mathbf{H}_{i} \mathbf{H}_{i}^{\dagger}
$$

onde $\mathbf{H}_{i}^{\dagger}=\left(\mathbf{H}_{i}^{\mathcal{H}} \mathbf{H}_{i}\right)^{-1} \mathbf{H}_{i}^{\mathcal{H}}$ é a pseudo-inversa da matriz $\mathbf{H}_{i}$

Na saída do banco de filtros as combinações de antenas são classificadas em ordem descendente da magnitude de projeção:

$$
\left\{p_{1}, p_{2}, \ldots, p_{N_{c}}\right\}=\underset{i}{\operatorname{argsort}}\left\|\mathbf{W}_{i} \mathbf{y}\right\|=\underset{i}{\operatorname{argsort}}\left\|\mathbf{H}_{i} \mathbf{w}_{i}\right\|,
$$


onde $\mathbf{w}_{i}=\mathbf{H}_{i}^{\dagger} \mathbf{y}$ e argsort é a função que ordena de forma decrescente os elementos do vetor em seu argumento e retorna os índices referentes às posições do vetor original.

\section{Fase 2. Geração dos candidatos de vetor de símbolos}

Nesta fase é gerada a lista de candidatos do vetor de símbolos transmitido. O tamanho da lista $\lambda \leq N_{c}$ é variável e vai depender da métrica obtida na fase 3 do algoritmo de detecção.

Nesta instância o detector proposto em [9] é composto por uma operação de redução de reticulado, seguida de um equalizador zero-forcing (ZF) e a detecção do vetor.

Para o j-ésimo candidato classificado na fase 1 é calculada uma matriz unimodal $\mathbf{T}_{p j}$ de $N_{a} \times N_{a}$ por um algoritmo de redução de bases como o algoritmo LLL proposto em [10] que opera na matriz $\mathbf{H}_{p j}$, produzindo uma matriz $\tilde{\mathbf{H}}_{p j}=\mathbf{H}_{p j} \mathbf{T}_{p j}$ com colunas aproximadamente ortogonais. Tem-se que o vetor recebido pode ser reescrito como:

$$
\mathbf{y}=\mathbf{H}_{p j} \mathbf{T}_{p j} \mathbf{T}_{p j}^{-1} \mathbf{b}+\mathbf{n}=\tilde{\mathbf{H}}_{p j} \mathbf{z}_{p j}+\mathbf{n},
$$

onde $\mathbf{z}_{p j}$ é o vetor de símbolos que resulta do mapeamento $\mathbf{z}_{p j}=\mathbf{T}_{p j}^{-1} \mathbf{b}$.

$\mathrm{O} j$-ésimo candidato, $j=1,2, \ldots, \lambda$ é gerado a partir de uma equalização linear aplicada em y. Para uma equalização ZF, obtém-se $\hat{\mathbf{z}}_{p j}^{0}=\tilde{\mathbf{H}}_{\mathbf{p j}}^{\dagger} \mathbf{y}$, $j=1,2, \ldots, \lambda$, onde $\tilde{\mathbf{H}}_{p j}^{\dagger}$ denota a pseudo inversa da matriz $\tilde{\mathbf{H}}_{p j}$. A discretização LR depois da equalização ZF produz o vetor detectado:

$$
\hat{\mathbf{z}}_{p j}=\alpha\left\lfloor\frac{1}{\alpha} \hat{\mathbf{z}}_{p j}^{0}-\frac{\beta}{\alpha} \mathbf{T}_{p j}^{-1} \mathbf{1}_{N_{a}}\right\rceil+\beta \mathbf{T}_{p j}^{-1} \mathbf{1}_{N_{a}}
$$

sendo $\hat{\mathbf{z}}_{p j}^{0}$ o sinal na saída do equalizador linear, $\mathbf{1}_{N_{a}}$ o vetor de comprimento $N_{a}$ com elementos iguais a um, $\alpha$ é igual ao módulo da separação mínima entre dois símbolos da constelação QAM e $\beta=1+j$. O candidato do vetor de símbolos está no espaço $\mathcal{S}^{N_{a}}$ e é obtido empregando a transformação:

$$
\mathbf{c}_{p j}=\operatorname{Disc}\left(\mathbf{T}_{p j} \hat{\mathbf{z}}_{\mathbf{p j}}\right), j=1,2, \ldots, \lambda
$$

onde $\operatorname{Disc}($.$) é a função que associa a cada elemento do vetor em seu$ argumento o ponto mais próximo na constelação de sinais da modulação empregada. 
Fase 3. Atualização de métrica de seleção de candidato e tamanho de lista

Na última fase do algoritmo de detecção a qualidade do candidato do vetor de símbolos gerado na fase 2 é avaliada encontrando a distância Euclidiana $\epsilon_{p j}$, que corresponde no caso à métrica ML com respeito ao vetor recebido:

$$
\epsilon_{p j}=\left\|\mathbf{y}-\mathbf{H}_{p j} \mathbf{c}_{p j}\right\|
$$

A qualidade do primeiro candidato $\left(p_{1}\right)$ é empregada para decidir o número $\lambda$ de candidatos que deverão ser avaliados para obter uma boa deteç̧ão. A cada novo candidato testado em sequência de acordo com o ordenamento estabelecido por 2-12, $\left(p_{j}=1,2, \ldots\right)$, o valor de $\lambda$ é atualizado. Este valor é obtido a partir de uma função custo que faz uso das estatísticas de $\epsilon^{2}$ para o caso de detecção sem erro. Neste caso o custo é $\|\mathbf{n}\|^{2}$ que é uma distribuição chi-quadrada com $2 N_{R}$ graus de liberdade, media $N_{R} \sigma^{2}$ e variância $N_{R} \sigma^{4}$. A métrica de qualidade $\phi\left(p_{i}\right)$ é definida como a diferença entre $\epsilon_{p j}^{2}$ e a média de $\|\mathbf{n}\|^{2}$, normalizada pelo desvio padrão:

$$
\phi\left(p_{j}\right)=\frac{\epsilon_{p j}^{2}-N_{R} \sigma^{2}}{\sqrt{N_{R} \sigma^{4}}}
$$

O comprimento $\lambda$ da lista é determinado por uma função exponencial de $\phi\left(p_{j}\right)$ com taxa de crescimento $l_{1}$ e um valor mínimo $l_{m i n}$ :

$$
\lambda\left(\phi\left(p_{j}\right)\right)=\left\lceil\max \left(l_{\text {min }}, \exp \left(l_{1} \phi\left(p_{j}\right)\right)\right)\right\rceil
$$

Os parâmetros $l_{\text {min }}$ e $l_{1}$ evitam iterações inecessárias. Quando a relação sinal-ruido (SNR) aumenta, menos candidatos que foram mal classificados na fase 1 são selecionados na fase 3 . Se são definidos $c_{l o}$ e $c_{h i}$ como o mínimo número de candidatos que serão processados para um valor baixo e alto de SNR, $\rho_{l o}$ e $\rho_{h i}$ respectivamente pode-se obter o valor mínimo de candidatos que serão processados para um valor arbitrário de SNR, $\rho$ : 


$$
l_{\min }=\frac{c_{h i}-c_{l o}}{\rho_{h i}-\rho_{l o}} \rho+c_{l o},
$$

onde $c_{h i}$ e $c_{l o}$ são fracções do número total de combinações de antenas. A taxa de crescimento é dado por $l_{1}=\frac{l_{\min }}{\sqrt{\bar{\rho}}}$.

Assim, quando um novo candidato $j=J$ é obtido, o vetor é considerado a melhor solução atual se a distância $\epsilon_{p J}$ é menor que a distância dos candidatos prévios, $j=1,2, \ldots, J-1$. Neste caso a distância $\epsilon_{\min }$ da melhor solução atual é atualizada. Para este candidato recente o comprimento da lista $\lambda$ é também atualizado. O algoritmo termina quando o número de candidatos testados é igual a $\lambda$. Supondo que o candidato $j=J$ é a melhor solução, o algoritmo retorna a combinação de antena respectiva, $\hat{k}=p_{J}$, e o vetor estimado, $\hat{\mathbf{b}}=c_{p J}$. Finalmente o vetor transmitido é reconstruído usando a tabela de mapeamento GSM, representada por $M_{G S M}$ :

$$
\hat{s}=M_{G S M}(\hat{k}, \hat{\mathbf{b}})
$$


Tabela 2.1: Exemplo de tabela de mapeamento

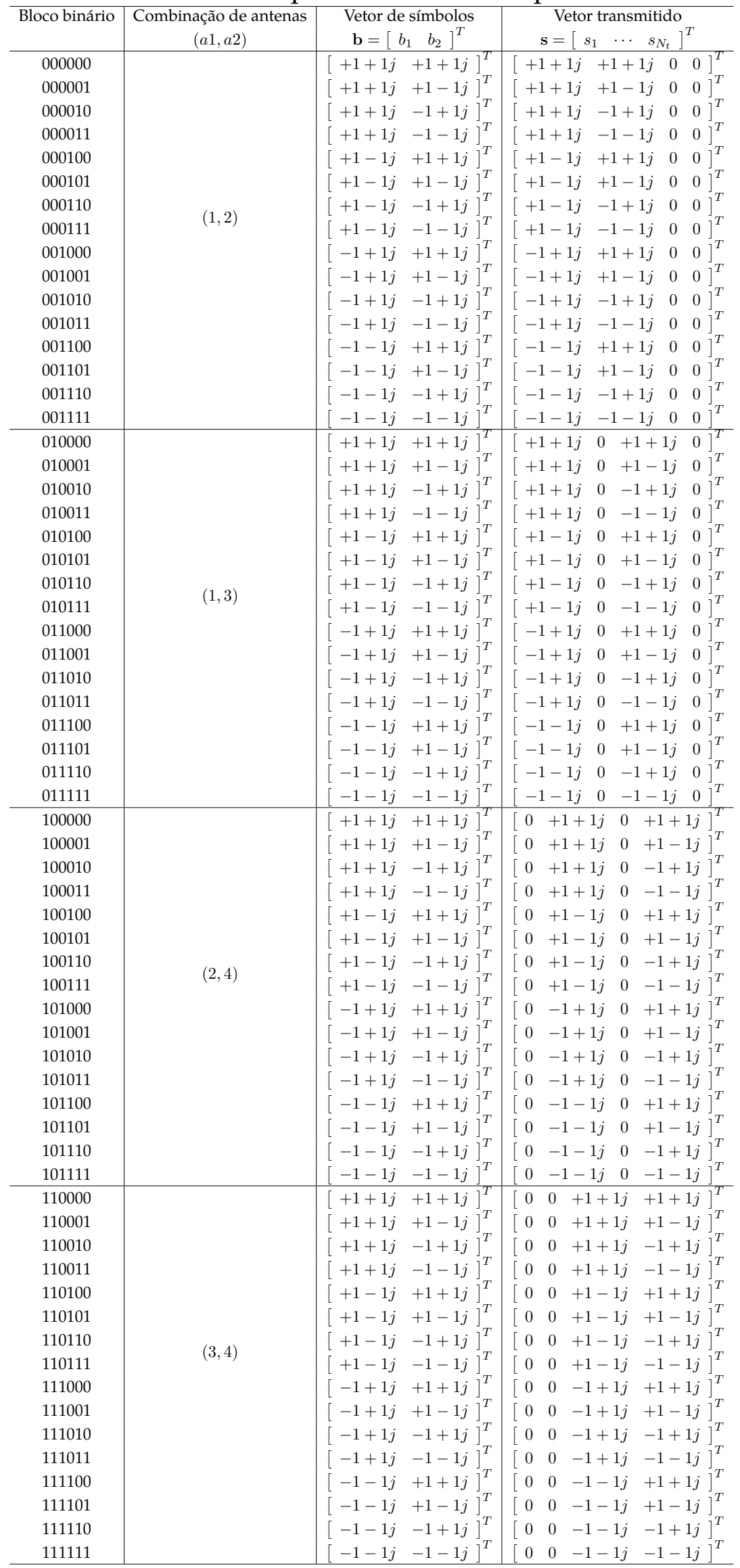




\section{3 \\ Técnicas de desacoplamento de sinais em enlace reverso para sistemas SM-MIMO}

Os sistemas MIMO são uma alternativa muito importante para as redes celulares de quinta geração (5G), redes para as quais espera-se um adensamento da quantidade de usuários com diferentes requerimentos de taxas de dados. Uma alternativa para a melhor detecção dos sinais transmitidos é a separação dos dispositivos dependendo dos diferentes requerimentos.

A separação de sinais é um dos principais temas de pesquisa dos sistemas MIMO e vai permitir processar o grande número de sinais recebidos de uma maneira mais simples, reduzir a interferência entre antenas e usuários, reduzir os efeitos de propagação, correlação, sombreamento, ruído térmico e degradação do sinal devido a imperfeições no hardware. Existem muitas técnicas criadas para eliminar as interferências como por exemplo os detectores de cancelamento sucessivo de interferência (SIC) [11] mas a complexidade computacional é muito alta para sistemas com um número grande antenas. É também destacável que se todos os sinais dos usuários fazem parte do processo de detecção de maneira conjunta, a ERB vai ter que empregar recursos de processamento desnecessários para alguns tipos de usuários que não precisam de um desempenho muito alto.

Neste capítulo são apresentadas algumas técnicas de desacoplamento de sinais que que vão permitir a separação das diferentes classes de usuários na estação rádio base (ERB) para posteriormente serem processadas dependendo da necessidade do usuário da rede.

As classes são formadas por usuários que compartem os mesmos requerimentos de dados e uma modulação complexa comum.

\subsection{Topologia do sistema MIMO GSM multiusuário e modelo de sinal do enlace reverso}

Nesta seção é apresentada a topologia do sistema MIMO GSM multiusuário e o modelo de sinal do enlace reverso. Com base no que será exposto são desenvolvidas as técnicas de desacoplamento.

Considera-se o cenário de canal de enlace reverso de um sistema MIMO multiusuário, cujos usuários podem ser divididos em $N$ diferentes classes. 
Capítulo 3. Técnicas de desacoplamento de sinais em enlace reverso para sistemas SM-MIMO

Estas classes reúnem usuários que possuem os mesmos requisitos sobre os dados transportados, logo são agrupados para o processo de desacoplamento.

Nesta dissertação, assume-se que cada usuário pertencente à mesma classe $n$ transmite seus dados empregando Modulação Espacial Generalizada, empregando $N_{t_{n}}$ antenas transmissoras, $N_{a_{n}}$ antenas ativas, resultando em $N_{c_{n}}$ combinações de antenas e com símbolos oriundos da mesma modulação digital, sorteados do conjunto $\mathbb{B}$. Esta consideração visa simplificar a notação do modelo, no entanto, as estratégias de desacoplamento e detecção do sinal aplicam-se a classes compostas por usuários com configurações de antenas distintas. A Figura 3.1 exibe a topologia típica do sistema MIMOGSM-MU.

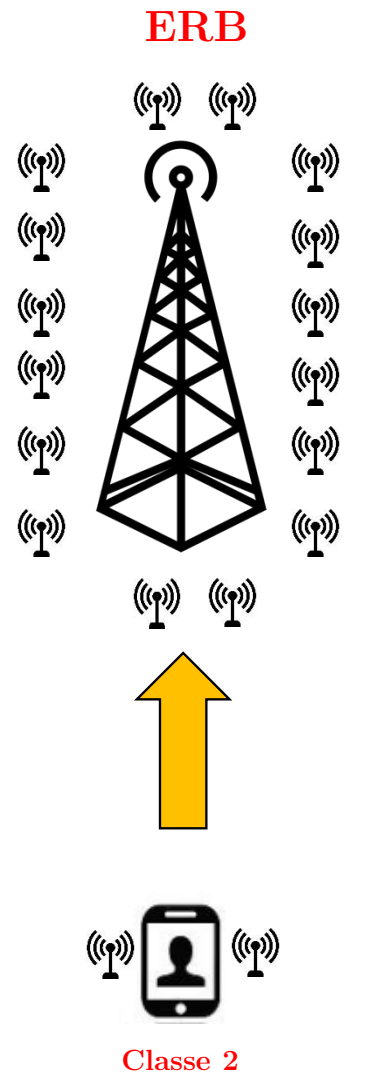

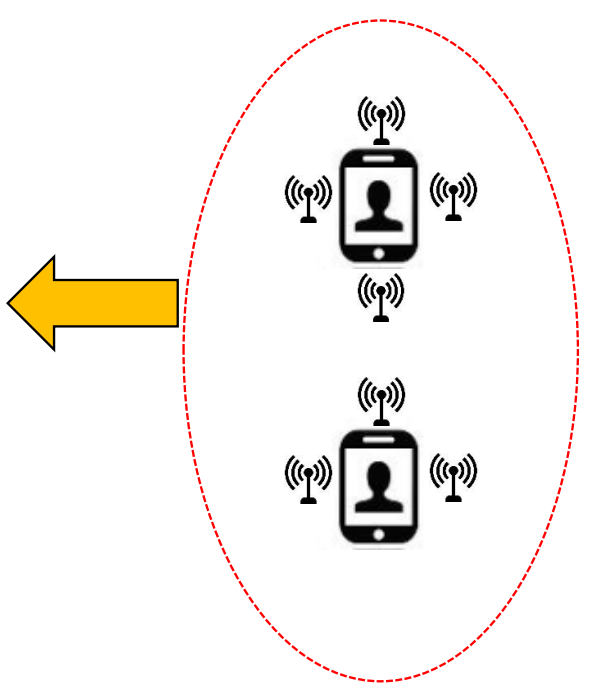

Classe 3

Figura 3.1: Modelo de rede sem fio.

Considere que a $n$-ésima classe tenha cardinalidade $\left|C_{n}\right|$, o que representa o número de usuários nela contida. Neste caso, o número total de antenas transmissoras de classe é $M_{t_{n}}=\left|C_{n}\right| N_{t_{n}}$, o número total de antenas ativas na classe é $M_{a_{n}}$ e o número total de antenas transmissoras no sistema igual a $M_{t}=\sum_{n=1}^{N} M_{t_{n}}$. Assim, o vetor de símbolos de modulação emitidos nas ante- 
Capítulo 3. Técnicas de desacoplamento de sinais em enlace reverso para sistemas SM-MIMO

nas ativas pelos usuários da $n$-ésima classe, $\mathbf{b}_{n}$, concatena os vetores de símbolos dos usuários da classe $\mathbf{b}_{n, i}$, produzindo $\mathbf{b}_{n}=\left[\mathbf{b}_{n, 1}^{T}, \mathbf{b}_{n, 2}^{T}, \ldots, \mathbf{b}_{n,\left|C_{n}\right|}^{T}\right]^{T}$, de dimensão $M_{a_{n}} \times 1$. O vetor de dados MIMO-GSM-MU transmitidos pelos usuários de classe $n$ é $\mathbf{s}_{n}=\left[\mathbf{s}_{n, 1}^{T}, \mathbf{s}_{n, 2}^{T}, \ldots, \mathbf{s}_{n,\left|C_{n}\right|}^{T}\right]^{T}$, de dimensão $M_{t_{n}} \times 1$.

Os vetores $\mathbf{b}_{n}$ e $\mathbf{s}_{n}$ se relacionam pela matriz de posicionamento dos símbolos da modulação empregada da $n$-ésima classe, $\mathcal{P}^{(n)}$, de dimensão $N_{t_{n}} \times\left|C_{n}\right| N_{c_{n}}$

$$
\mathbf{s}_{n}=\mathcal{P}^{(n)} \mathbf{b}_{n}
$$

Considere que o primeiro usuário da classe $n$ use a combinação de antenas $p_{1}$, o segundo usuário use a combinação $p_{2}$, o $k$-ésimo usuário use a combinação $p_{k}$, etc.

Como apresentado no Capítulo 2, para o caso MIMO-GSM com usuário simples, seja $\mathbf{P}_{p_{k}}^{(n)}$ a matriz $N_{t_{n}} \times N_{c_{n}}$ de posicionamento dos elementos de $\mathbf{b}_{n, k}$ em $\mathbf{s}_{n, k}$. No sistema MIMO-GSM-MU, a matriz $\mathcal{P}^{(n)}$ de dimensão $N_{t_{n}} \times\left|C_{n}\right| N_{c_{n}}$, tem a forma:

$$
\mathcal{P}^{(n)}=\left[\begin{array}{ll}
\mathbf{P}_{p_{1}}^{n} & \mathbf{P}_{p_{2}}^{n} \ldots \mathbf{P}_{p_{\left|c_{n}\right|}}^{n}
\end{array}\right]
$$

Os elementos de $\mathbf{s}_{n}$ pertencem ao conjunto $\mathcal{S}_{n}$ :

$$
\mathcal{S}_{n}=\left\{\mathcal{P}^{(n)} \mathbf{b}_{n} \mid p_{1}, p_{2}, \ldots, p_{\left|c_{n}\right|} \in 1,2, \ldots, N_{c_{n}}, \mathbf{b}_{n} \in \mathbb{B}^{M_{a_{n}}}\right\}
$$

Ao atravessar o canal MIMO multiusuário, o sinal que chega à ERB relaciona-se com os sinais transmitidos pelos $\sum_{n=1}^{N}\left|C_{n}\right|$ usuários por:

$$
\mathbf{y}=\sum_{n=1}^{N} \sum_{k=1}^{\left|C_{n}\right|} \mathbf{H}_{n, k} \mathbf{s}_{n, k}+\mathbf{n} .
$$

onde $\mathbf{H}_{n, k}$ é a matriz $N_{r} \times N_{t_{n}}$ de canal que representa a ligação entre as $N_{t_{n}}$ antenas do $k$-ésimo usuário da $n$-ésima classe e as $N_{r}$ antenas receptoras da ERB. $\mathrm{O}$ vetor de ruido Gaussiano aditivo tem média nula e matriz covariancia $\mathbf{K}_{n}=\sigma_{n}^{2} \mathbf{I}_{N_{r}}$. 
Capítulo 3. Técnicas de desacoplamento de sinais em enlace reverso para sistemas SM-MIMO

A expressão 3-4 pode ser reescrita assim:

$$
\mathbf{y}=\sum_{n=1}^{N} \mathbf{H}_{n} \mathbf{s}_{n}+\mathbf{n},
$$

onde $\mathbf{H}_{n}=\left[\begin{array}{lll}\mathbf{H}_{n, 1} & \mathbf{H}_{n, 2} \ldots \mathbf{H}_{n,\left|C_{n}\right|}\end{array}\right]$ e $\mathbf{s}_{n}=\left[\begin{array}{ll}\mathbf{s}_{n, 1}^{T} & \mathbf{s}_{n, 2}^{T} \ldots \mathbf{s}_{n, \mid C_{n}}^{T}\end{array}\right]^{T}$ representam a matriz de canal $N_{r} \times M_{t_{n}}$ que conecta os usuários da classe $n$ com a ERB e o vetor de símbolos transmitido por todos os usuários da classe $n$, respectivamente. Finalmente o vector recebido pode ser expresso da seguinte maneira:

$$
\mathbf{y}=\mathbf{H} \mathbf{s}+\mathbf{n},
$$

onde $\mathbf{H}=\left[\begin{array}{lll}\mathbf{H}_{1} & \mathbf{H}_{2} \ldots \mathbf{H}_{N}\end{array}\right]$ de dimensão $N_{r} \times M_{t}$ e $\mathbf{s}=\left[\begin{array}{lll}\mathbf{s}_{1}^{T} & \mathbf{s}_{2}^{T} \ldots \mathbf{s}_{N}^{T}\end{array}\right]^{T}$ $M_{t} \times 1$. Considerando que os vetores de símbolos dos usuários, $\mathbf{s}_{n, k}$, fazem transmissão MIMO-GSM com símbolos com energia $E_{s_{n}}, \operatorname{logo} \mathbb{E}\left[\mathbf{s}_{n, k}^{H} \mathbf{s}_{n, k}\right]=$ $N_{a_{n}} E_{s_{n}}$. Assim, para o vetor dos dados de todos os usuários, $\mathbf{s}$, tem-se $\mathbb{E}\left[\mathbf{s}^{H} \mathbf{s}\right]=\left|C_{1}\right| N_{a_{1}} E_{s_{1}}+\left|C_{2}\right| N_{a_{2}} E_{s_{2}}+\cdots+\left|C_{N}\right| N_{a_{N}} E_{s_{N}}$. Pela simplicidade da notação e das análises que seguirão, supõe-se que os usuários emitem símbolos com a mesma energia média, $E_{s}$, assim $\mathbb{E}\left[\mathbf{s}^{H} \mathbf{s}\right]=E_{s} \sum_{n=1}^{N}\left|C_{n}\right| N_{a_{n}}$. Assume-se também que a ERB possui o perfeito conhecimento do canal $\mathbf{H}$.

\subsection{Detecção desacoplada de sinais - DSD}

A primeira técnica considerada neste trabalho é apresentada em [12]. Suponha que deseja-se realizar a detecção dos usuários da n-ésima classe em meio ao vetor de dados recebidos $\mathbf{y}$, que contém todos os usuários. Considere $\mathcal{A}$ o subespaço vetorial gerado pelas colunas da matriz de canal referentes aos usuários das demais classes e $\mathcal{A}^{\perp}$ o subespaço vetorial ortogonal a $\mathcal{A}$. Para proceder com a remoção dos demais usuários interferentes sobre a classe $n$, é empregada uma operação linear para projetar y em um subespaço próximo a $\mathcal{A}^{\perp}$.

Em DSD é calculada uma matriz $\mathbf{A}_{n}$ empregando uma inversão de canal e a decomposição RQ [12] [13], para desacoplar o sinal da n-ésima classe desejada dos sinais das demais classes.

A ideia é obter a matriz $\mathbf{A}_{n}$, que desempenha o desacoplamento, é tal que $\mathbf{A}_{n}^{T}$ está localizada no espaço nulo à esquerda de $\tilde{\mathbf{H}}_{n}$, ou seja:

$$
\mathbf{A}_{n} \tilde{\mathbf{H}}_{n}=\mathbf{0}, \forall_{n} \in(1, \ldots, N),
$$

onde $\tilde{\mathbf{H}}_{n} \in \mathbb{C}^{N_{r} \times\left(M_{t}-M_{t_{n}}\right)}$ é uma matriz construída excluindo da matriz $\mathbf{H}$ a matriz de canal da classe desejada. Assim: 
Capítulo 3. Técnicas de desacoplamento de sinais em enlace reverso para sistemas SM-MIMO

$$
\tilde{\mathbf{H}}_{n}=\left[\begin{array}{lll}
\mathbf{H}_{1} \ldots \mathbf{H}_{n-1} & \mathbf{H}_{n+1} \ldots \mathbf{H}_{N}
\end{array}\right]
$$

O primeiro passo para determinar $\mathbf{A}_{n}$ é obter a matriz de inversão de canal MMSE da matriz de canal combinada $\mathbf{H}$ :

$$
\begin{gathered}
\mathbf{H}^{\dagger}=\mathbf{H}^{\mathcal{H}}\left(\mathbf{H H}^{\mathcal{H}}+\sigma^{2} \mathbf{I}\right)^{-1} \\
\mathbf{H}^{\dagger}=\left[\left(\mathbf{H}_{1}^{0}\right)^{T}\left(\mathbf{H}_{2}^{0}\right)^{T} \ldots\left(\mathbf{H}_{N}^{0}\right)^{T}\right]^{T}
\end{gathered}
$$

onde $\sigma^{2}=\frac{\sigma_{n}^{2}}{\sigma_{s}^{2}}, \quad \mathbf{H}^{\dagger} \in \mathbb{C}^{M_{t} \times N_{r}}$ e $\mathbf{H}_{n}^{0} \in \mathbb{C}^{M_{t_{n}} \times N_{r}}$.

Pode-se dizer então que a matriz $\left(\mathbf{H}_{n}^{0}\right)^{T}$ está aproximadamente no espaço nulo à esquerda de $\tilde{\mathbf{H}}_{n}$ :

$$
\mathbf{H}_{n}^{0} \tilde{\mathbf{H}}_{n} \approx \mathbf{0}, \forall_{n} \in(1, \ldots, N)
$$

No procedimento proposto em [12] é feita uma decomposição RQ em $\mathbf{H}_{n}^{0}$. Ou seja,

$$
\mathbf{H}_{n}^{0}=\mathbf{R}_{n} \mathbf{Q}_{n}, \quad \forall n \in(1, \ldots, N)
$$

onde $\mathbf{R}_{n} \in \mathbb{C}^{M_{t_{n}} \times M_{t_{n}}}$ é uma matriz triangular superior e $\mathbf{Q}_{n} \in \mathbb{C}^{M_{t_{n}} \times N_{r}}$ é uma matriz com linhas ortonormais e colunas que formam aproximadamente uma base para o espaço nulo à esquerda de $\tilde{\mathbf{H}}_{n}$ :

$$
\mathrm{Q}_{n} \tilde{\mathbf{H}}_{n} \approx \mathbf{0}
$$

Assim, $\mathbf{A}_{n}=\mathbf{Q}_{n}$ pode ser empregada como a matriz que efetua aproximadamente a separação dos usuários da classe $n$ :

$$
\mathbf{y}_{n}=\mathbf{A}_{n} \mathbf{y}
$$

O vetor y definido em (3-6) pode ser reescrito na forma: 
Capítulo 3. Técnicas de desacoplamento de sinais em enlace reverso para sistemas SM-MIMO

$$
\mathbf{y}=\mathbf{H}_{n} \mathbf{s}_{n}+\sum_{m=1, m \neq n}^{N} \mathbf{H}_{m} \mathbf{s}_{m}+\mathbf{n}
$$

onde $\mathbf{H}_{n}$ e $\mathbf{s}_{n}$ representam a matriz do canal e o vetor de símbolos da n-ésima classe de usuário e o termo $\sum_{m=1, m \neq n}^{N} \mathbf{H}_{m} \mathbf{s}_{m}$ é a interferência causada pelos usuários das demais classes.

Utilizando-se (3-14) e (3-15) tem-se:

$$
\begin{aligned}
& \mathbf{y}_{n}=\mathbf{A}_{n} \mathbf{H}_{n} \mathbf{s}_{n}+\mathbf{A}_{n} \sum_{m=1, m \neq n}^{N} \mathbf{H}_{m} \mathbf{s}_{m}+\mathbf{A}_{n} \mathbf{n}, \\
& \mathbf{y}_{n}=\mathbf{Q}_{n} \mathbf{H}_{n} \mathbf{s}_{n}+\mathbf{Q}_{n} \sum_{m=1, m \neq n}^{N} \mathbf{H}_{m} \mathbf{s}_{m}+\mathbf{Q}_{n} \mathbf{n},
\end{aligned}
$$

onde $\mathbf{y}_{n} \in \mathbb{C}^{M_{t_{n}} \times 1}$ é o vetor de sinal recebido equivalente para a classe $n$ e o termo $\mathbf{Q}_{n} \sum_{m=1, m \neq n}^{N} \mathbf{H}_{m} \mathbf{s}_{m} \approx 0$. Resulta então:

$$
\mathbf{y}_{n}=\check{\mathbf{H}}_{n} \mathbf{s}_{n}+\mathbf{n}_{n}, \quad \forall n \in(1, \ldots, N),
$$

onde $\check{\mathbf{H}}_{n}=\mathbf{Q}_{n} \mathbf{H}_{n} \in \mathbb{C}^{M_{t_{n}} \times M_{t_{n}}}$ é a matriz de canal equivalente da $n$-ésima classe de usuário depois da DSD e $\mathbf{n}_{n}=\mathbf{Q}_{n} \sum_{m=1, m \neq n}^{N} \mathbf{H}_{m} \mathbf{s}_{m}+\mathbf{Q}_{n} \mathbf{n}$ é o vetor de ruído equivalente. Ressalte-se que como $\mathrm{Q}_{n}$ tem linhas ortonormais, o vetor de ruido $\mathbf{n}^{\prime}=\mathbf{Q}_{n} \mathbf{n}$ permanece branco com matriz autocorrelação $\mathbf{K}_{n}=\mathbb{E}\left[\mathbf{n}^{\prime} \mathbf{n}^{\prime \mathcal{H}}\right]=\sigma_{n}^{2} \mathbf{I}_{M_{t_{n}}}$

É importante ressaltar que os processos de detecção que envolvam o desacoplamento do sinal em grupos (ou classes) de usuários estabelecem um importante compromisso entre qualidade da detecção e complexidade do receptor. Isto deve-se ao fato de que diferentes escolhas de agrupamento dos usuários em classes irá impor esforços computacionais diferentes e que são crescentes com a melhora do desempenho de detecção. Tome como exemplo o caso do enlace reverso de um sistema GSM-MIMO-MU que opera com quatro usuários. Estes podem ser submetidos a diferentes formas de classificação, entre elas, as duas opções selecionadas (número de classes x usuários por classe): quatro classes com um usuário cada (caso $4 \times 1$ ) ou duas classes com dois usuários cada (caso $2 \times 2$ ). Para efeito de se simplificar o exemplo numérico a seguir, admitimos que todos os usuários possuem o mesmo nú- 


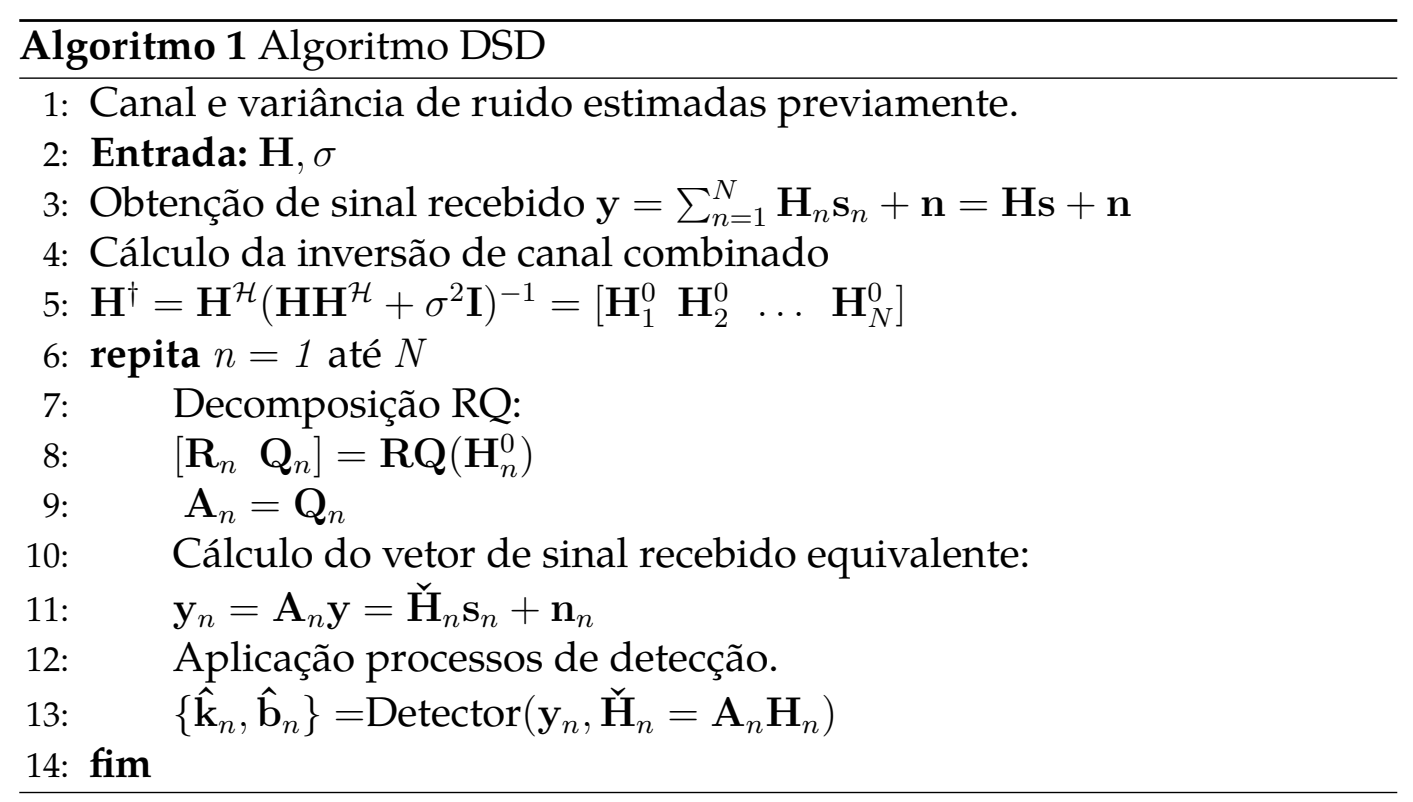

mero de antenas transmissoras e ativas, $N_{t_{n}}$ e $N_{a_{n}}$, o mesmo número de combinações de antenas e ordem da modulação, $N_{c}$ e $M$. Admitindo um receptor composto por um desacoplador DSD, seguido de um detector ótimo vamos ter que:

O caso 4x1 irá realizar (em termos de número de multiplicações complexas):

-quatro decomposições QR de matrizes de tamanho $N_{t_{n}} \times N_{r}$, totalizando uma complexidade aproximada de $8 N_{t_{n}} N_{r}^{2}$.

-quatro multiplicações $\mathbf{Q}_{n} \tilde{\mathbf{H}}_{n}$, matrizes $\left(N_{t_{n}} \times N_{r}\right) .\left(N_{r} \times 3 N_{t_{n}}\right)$, totalizando $12 N_{t_{n}}^{2} N_{r}$.

- quatro detecções ML, cada uma testando $N_{c_{n}} M^{N_{a_{n}}}$ hipóteses, totalizando $4\left(N_{t_{n}}+N_{t_{n}}^{2}\right) N_{c} M^{N_{a_{n}}}$.

O caso $2 \times 2$ realizará:

- duas decomposições QR de matrizes de tamanho $2 N_{t_{n}} \times N_{r}$ totalizando $8 N_{t_{n}}^{2} N_{r}$.

-duas multiplicações $\mathbf{Q}_{n} \tilde{\mathbf{H}}_{n}$, matrizes $\left(2 N_{t_{n}} \times N_{r}\right) .\left(N_{r} \times 2 N_{t_{n}}\right)$, totalizando $8 N_{t_{n}}^{2} N_{r}$-duas detecções ML, cada um testando $N_{c}^{2} M^{2 N_{a}}$ hipóteses, totalizando $2\left(2 N_{t_{n}}+\left(2 N_{t_{n}}\right)^{2}\right) N_{c}^{2} M^{N_{a}}$.

Este exemplo numérico evidencia que o maior custo computacional recai sobre o detector $\mathrm{ML}$, tornando o caso 2x2 mais custoso que o $4 \times 1$.

O algoritmo 1 apresenta de maneira resumida o algoritmo DSD. 
Capítulo 3. Técnicas de desacoplamento de sinais em enlace reverso para sistemas SM-MIMO

\subsection{Decomposição em valores singulares - SVD}

Nesta seção é apresentada outra opção de desacoplamento de sinais [12]. A decomposição em valores singulares (SVD) permite calcular as bases para o espaço nulo à esquerda de $\tilde{\mathbf{H}}_{n}$. Aplicando a decomposição em $\tilde{\mathbf{H}}_{n}$ temos:

$$
\tilde{\mathbf{H}}_{n}=\tilde{\mathbf{U}}_{n} \tilde{\Sigma}_{n} \tilde{\mathbf{V}}_{n}^{\mathcal{H}}
$$

onde $\tilde{\Sigma}_{n} \in \mathbb{C}^{N_{r} \times\left(M_{t}-M_{t_{n}}\right)}$ é uma matriz diagonal retangular com os valores singulares de $\tilde{\mathbf{H}}_{n}$ na diagonal, $\tilde{\mathbf{U}}_{n} \in \mathbb{C}^{N_{r} \times N_{r}}$ e $\tilde{\mathbf{V}}_{n}^{\mathcal{H}} \in \mathbb{C}^{\left(M_{t}-M_{t_{n}}\right) \times\left(M_{t}-M_{t_{n}}\right)}$ são matrizes unitárias. Se $r_{n}$ é o posto de $\tilde{\mathbf{H}}_{n}, r_{n}=\operatorname{rank}\left(\tilde{\mathbf{H}}_{n}\right) \leq M_{t}-M_{t_{n}}$ a decomposição SVD pode ser expressa da forma:

$$
\tilde{\mathbf{H}}_{n}=\left[\begin{array}{ll}
\tilde{\mathbf{U}}_{1, n} & \tilde{\mathbf{U}}_{0, n}
\end{array}\right] \tilde{\Sigma}_{n}\left[\begin{array}{ll}
\tilde{\mathbf{V}}_{1, n} & \tilde{\mathbf{V}}_{0, n}
\end{array}\right]^{\mathcal{H}},
$$

onde $\tilde{\mathbf{U}}_{0, n} \in \mathbb{C}^{N_{r} \times\left(N_{r}-r_{n}\right)}$ e $\tilde{\mathbf{V}}_{0, n}^{\mathcal{H}} \in \mathbb{C}^{\left(M_{t}-M_{t_{n}}-r_{n}\right) \times\left(M_{t}-M_{t_{n}}\right)}$ formam bases ortogonais para o espaço nulo à esquerda e o espaço nulo de $\tilde{\mathbf{H}}_{n}$, respectivamente. A alternativa para a equação (3-7) seria:

$$
\mathbf{A}_{n}=\tilde{\mathbf{U}}_{0, n}^{\mathcal{H}}
$$

Neste casso, $\mathbf{y}_{n}=\tilde{\mathbf{U}}_{\mathbf{0}, \mathbf{n}}^{\mathcal{H}} \cdot \mathbf{y}$, com $\mathbf{y}$ dado por (3-15).

Ressalte-se que, diferentemente da técnica DSD, o desacoplamento SVD remove perfeitamente as componentes de interferência sobre a classe desejada, ou seja $\tilde{U}_{0, n}^{\mathcal{H}} \sum_{m=1, m \neq n}^{N} \mathbf{H}_{m} \mathbf{s}_{m}=0$. Isto ocorre pois $\tilde{\mathbf{U}}_{0, n}^{\mathcal{H}}$ está exatamente no espaço nulo â esquerda de $\tilde{\mathbf{H}}_{n}$

No algoritmo 2 é detalhado o desacoplamento SVD.

\subsection{Desacoplamento Zero Forcing-Maximum Likelihood (ZF-ML)}

Nesta seção é descrito outro método de desacoplamento estudado na dissertação nomeado "Desacoplamento ZF-ML". O método faz primeiro uma inversão de canal zero forcing e depois faz uma detecção ML.

Lembrando que o vetor de sinal recebido tem a forma apresentada na seguinte equação:

$$
\mathbf{y}=\mathbf{H s}+\mathbf{n}
$$




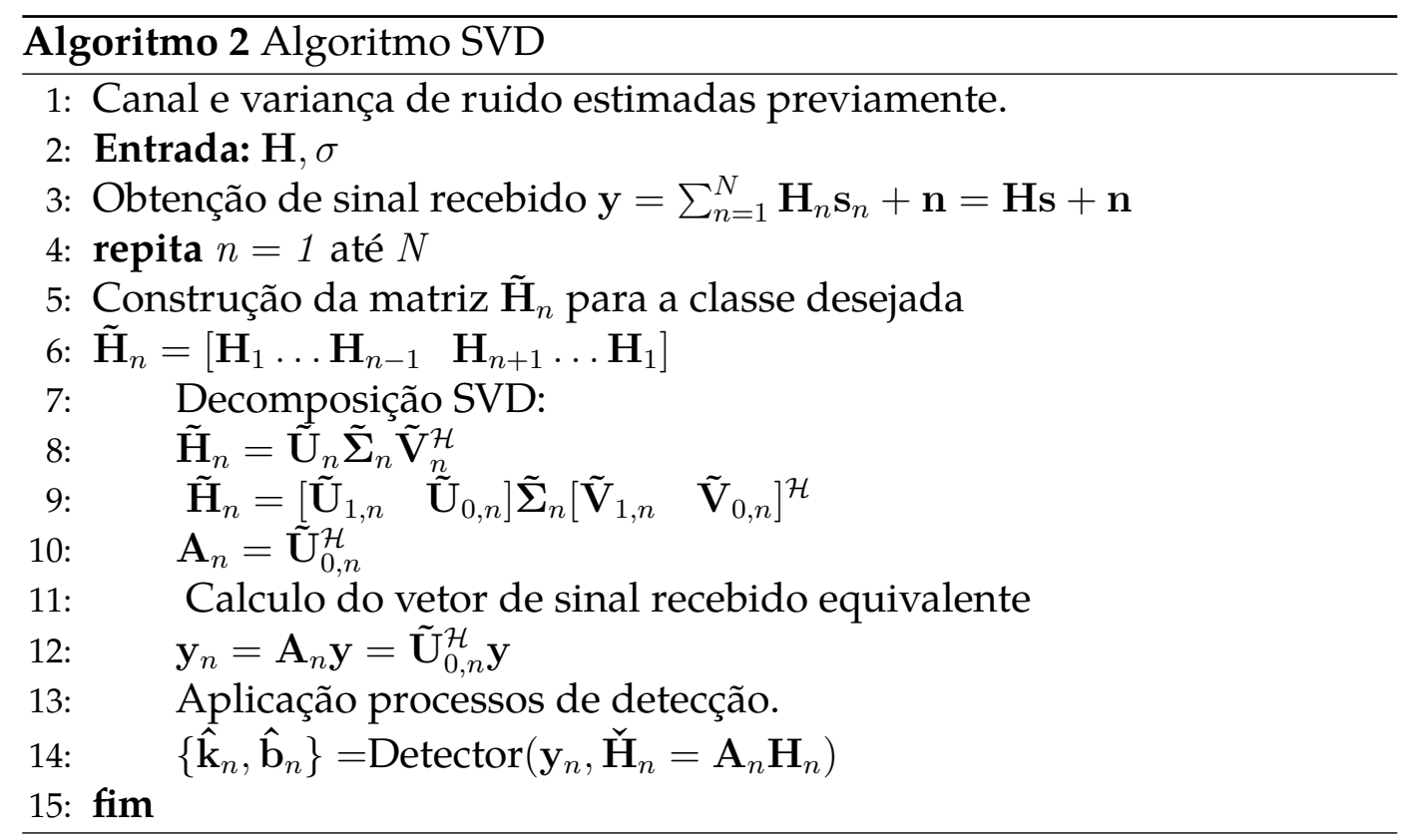

O primeiro passo para efetuar o desacoplamento das classes é calcular a inversão de canal ZF da matriz de canal combinada $\mathbf{H}$ :

$$
\mathbf{H}^{\dagger}=\left(\mathbf{H}^{\mathcal{H}} \mathbf{H}\right)^{-1} \mathbf{H}^{\mathcal{H}}
$$

onde $\mathbf{H}^{\dagger} \in \mathbb{C}^{M_{t} \times N_{r}}$

Para o desacoplamento ZF a matriz que efetua aproximadamente a separação dos usuários da classe $n$ é definida como: $\mathbf{A}_{n}=\mathbf{H}^{\dagger}$.

O novo vetor de sinal recebido $\tilde{\mathbf{y}} \in \mathbb{C}^{M_{t} \times 1}$ é apresentado na seguinte equação:

$$
\begin{gathered}
\tilde{\mathbf{y}}=\mathbf{H}^{\dagger} \mathbf{y} \\
\tilde{\mathbf{y}}=\mathbf{H}^{\dagger}(\mathbf{H} \mathbf{s}+\mathbf{n}) \\
\tilde{\mathbf{y}}=\mathbf{s}+\mathbf{H}^{\dagger} \mathbf{n} \\
\tilde{\mathbf{y}}=\mathbf{s}+\mathbf{n}^{\prime},
\end{gathered}
$$

onde $\mathbf{n}^{\prime}=\left(\mathbf{H}^{\mathcal{H}} \mathbf{H}\right)^{-1} \mathbf{H}^{\mathcal{H}} \mathbf{n}$ é o vetor de ruído colorido $\in \mathbb{C}^{M_{t} \times 1}$ de matriz de 
Capítulo 3. Técnicas de desacoplamento de sinais em enlace reverso para sistemas SM-MIMO

covariância $\mathbf{K}_{n^{\prime}}$ dada por:

$$
\begin{gathered}
\mathbf{K}_{n^{\prime}}=\mathbb{E}\left[\mathbf{n}^{\prime} \mathbf{n}^{\prime \mathcal{H}}\right]=\mathbb{E}\left[\mathbf{H}^{\dagger} \mathbf{n}^{\prime} \mathbf{n}^{\prime \mathcal{H}} \mathbf{H}^{\dagger^{\mathcal{H}}}\right] \\
\mathbf{K}_{n^{\prime}}=\sigma^{2}\left(\mathbf{H}^{\dagger} \mathbf{H}^{\dagger^{\mathcal{H}}}\right) \\
\mathbf{K}_{n^{\prime}}=\sigma^{2}\left(\mathbf{H}^{\mathcal{H}} \mathbf{H}\right)^{-1}
\end{gathered}
$$

A remoção de interferência entre usuários através da remoção de $\mathbf{H}$ em (3-27) permite que o problema de detecção seja partido nas $N$ classes.

A detecção do vetor de dados das classes é feito através de detectores ML. Esta estrategia é subótima para a solução de (3-22) mas é o detector ótimo para as classes.

Considere o vetor na saída do equalizador ZF e o vetor de ruído colorido $\mathbf{n}^{\prime}$ estruturados em subvetores de comprimento igual ao comprimento das classes:

$$
\begin{aligned}
\tilde{\mathbf{y}} & =\left[\begin{array}{llll}
\tilde{\mathbf{y}}_{1}^{T} & \tilde{\mathbf{y}}_{2}^{T} & \ldots & \tilde{\mathbf{y}}_{N}^{T}
\end{array}\right]^{T} \\
\mathbf{n}^{\prime} & =\left[\begin{array}{llll}
\mathbf{n}_{1}^{\prime T} & \mathbf{n}_{2}^{\prime T} & \ldots & \mathbf{n}_{n}^{\prime T}
\end{array}\right]^{T}
\end{aligned}
$$

O detector ML ótimo para a classe $n$ em presença de ruído colorido com matriz covariância $\mathbf{K}_{\mathbf{n}_{\mathbf{n}}^{\prime}}$ equivale a um detector de mínima distância do vetor de dados $\mathbf{y}_{n}$ após a aplicação do filtro branqueador de ruído $\mathbf{K}_{\mathbf{n}_{\mathbf{n}}^{\prime}}{ }^{-1 / 2}$, resultando no vetor $\tilde{\mathbf{y}}_{w_{n}}=\mathbf{K}_{n_{n}^{\prime}}^{-1 / 2} \tilde{\mathbf{y}}_{n}$ :

$$
\begin{gathered}
\tilde{\mathbf{y}}_{w_{n}}=\mathbf{K}_{\mathbf{n}_{\mathbf{n}}^{\prime}}{ }^{-1 / 2}\left(\mathbf{s}_{n}+\mathbf{n}_{n}^{\prime}\right) \\
\tilde{\mathbf{y}}_{w_{n}}=\mathbf{K}_{\mathbf{n}_{\mathbf{n}}^{\prime}}^{-1 / 2} \mathbf{s}_{n}+\mathbf{n}_{W_{n}}^{\prime}
\end{gathered}
$$


Capítulo 3. Técnicas de desacoplamento de sinais em enlace reverso para sistemas SM-MIMO

onde $\mathbf{n}_{W_{n}}^{\prime}$ é um vetor de ruído Gaussiano branco. A expressão do detector ML para a $n$-ésima classe é portanto dada por:

$$
\hat{\mathbf{s}}_{n}^{M L}=\underset{\mathbf{s}_{n} \in \mathcal{S}_{n}}{\arg \min }\left\|\tilde{\mathbf{y}}_{w_{n}}-\mathbf{K}_{\mathbf{n}_{\mathbf{n}}^{\prime}}{ }^{-1 / 2} \mathbf{s}_{n}\right\|^{2}=\underset{\mathbf{s}_{n} \in \mathcal{S}_{n}}{\arg \min }\left(\tilde{\mathbf{y}}_{n}-\mathbf{s}_{n}\right)^{H} \mathbf{K}_{\mathbf{n}_{\mathbf{n}}^{\prime}}{ }^{-1}\left(\tilde{\mathbf{y}}_{n}-\mathbf{s}_{n}\right)
$$

onde o conjunto $\mathcal{S}_{n}$ é definido em (3-3).

A matriz $\mathbf{K}_{\mathbf{n}_{\mathbf{n}}^{\prime}}$ é identificada como a $n$-ésima submatriz de dimensão $M_{t_{n}} \times M_{t_{n}}$ sobre a diagonal principal de $\mathbf{K}_{n^{\prime}}$, dada por 3-28.

$$
\mathbf{K}_{n^{\prime}}=\left[\begin{array}{cccc}
\mathbf{K}_{n_{1}^{\prime}} & x & x & x \\
x & \mathbf{K}_{n_{2}^{\prime}} & x & x \\
x & x & \ddots & x \\
x & x & x & \mathbf{K}_{n_{n}^{\prime}}
\end{array}\right]
$$

É possível demonstrar que a detecção dos símbolos dos usuários realizada com o receptor baseado no esquema de desacoplamento ZF seguido do detector ML (ZF-ML) é equivalente ao receptor que emprega do desacoplamento SVD seguido do detector ML (apresentado na Seção 2.3.1, para ruído branco). Esta prova é apresentada no Apêndice 1. 


\section{Avaliação de desempenho e complexidade}

Neste capítulo são apresentados os resultados obtidos na avaliação de desempenho (i.e., bit error rate BER) e complexidade computacional(i.e., número médio de flops requeridos por vetor de símbolos detectado) para os detectores estudados no Capítulo 2 empregando as diferentes técnicas de desacoplamento estudadas no Capítulo 3.

O cenário considerado para a realização das simulações é um sistema MIMO com enlace reverso e 4 usuários utilizando modulação espacial (SM), cada um com 4 antenas das quais duas são ativadas por transmissão. Na estação radio base tem-se 16 antenas para a recepção. A modulação empregada na transmissão é QPSK. Na Figura 4.1 pode-se observar o cenário de simulação.

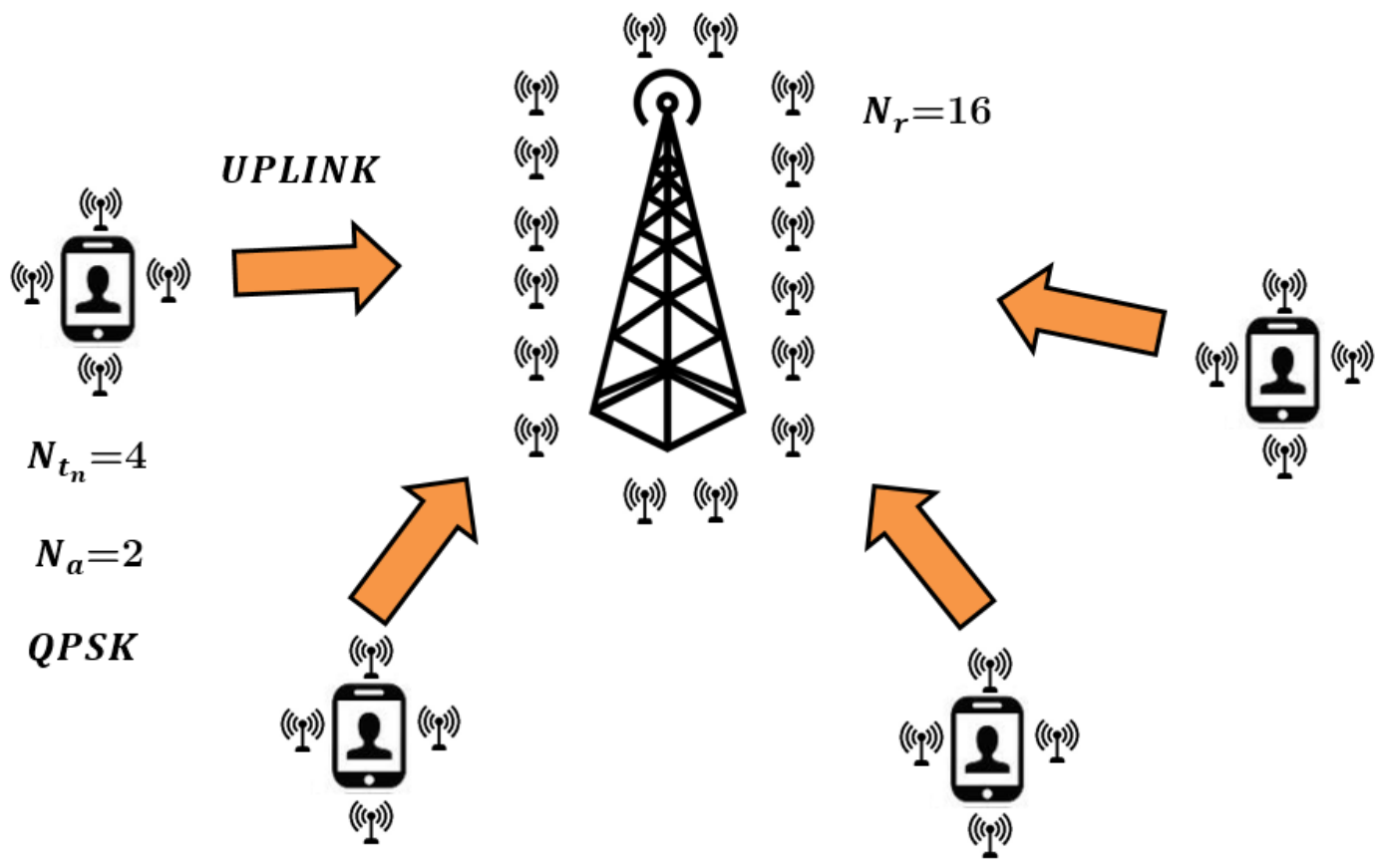

Figura 4.1: Cenário de simulação

Os elementos da matriz de canal $\mathbf{H}$ são modelados como variáveis aleatórias estatisticamente independentes Gaussianas complexas circularmente 
simétricas todas com média zero e variância unitária. A suposição feita resulta em enlaces transmissor-receptor de ganho unitário e modela o desvanecimento de Rayleigh da amplitude do sinal recebido, desvanecimento típico de canais rádio móveis e ricos em espalhadores do sinal [14].

\subsection{Usuários}

Primeiramente foi testado o desempenho dos detectores para o vector recebido na estação base sem a aplicação de nenhuma técnica de desacoplamento. O resultado é apresentado na Figura 4.2, na qual pode-se observar que, como esperado, o detector ML apresenta desempenho superior aos dos detectores Project Based List com e sem redução de reticulado. Em termos de complexidade computacional, entretanto o custo do detector ML é muito mais alto que os outros detectores como, evidenciado na Figura 4.3.

A relação sinal-ruído (signal-to-noise ratio SNR) é definida como:

$$
S N R=10 \log _{10} \frac{N_{u} N_{a} \sigma_{s}^{2}}{\sigma_{n}^{2}}
$$

onde $N_{u}$ é o número total de usuários do sistema, $N_{a}$ é o número de antenas ativas por usuário, $\sigma_{s}^{2}$ é a variância comum dos símbolos transmitidos e $\sigma_{n}^{2}$ é a variância de ruido no receptor.

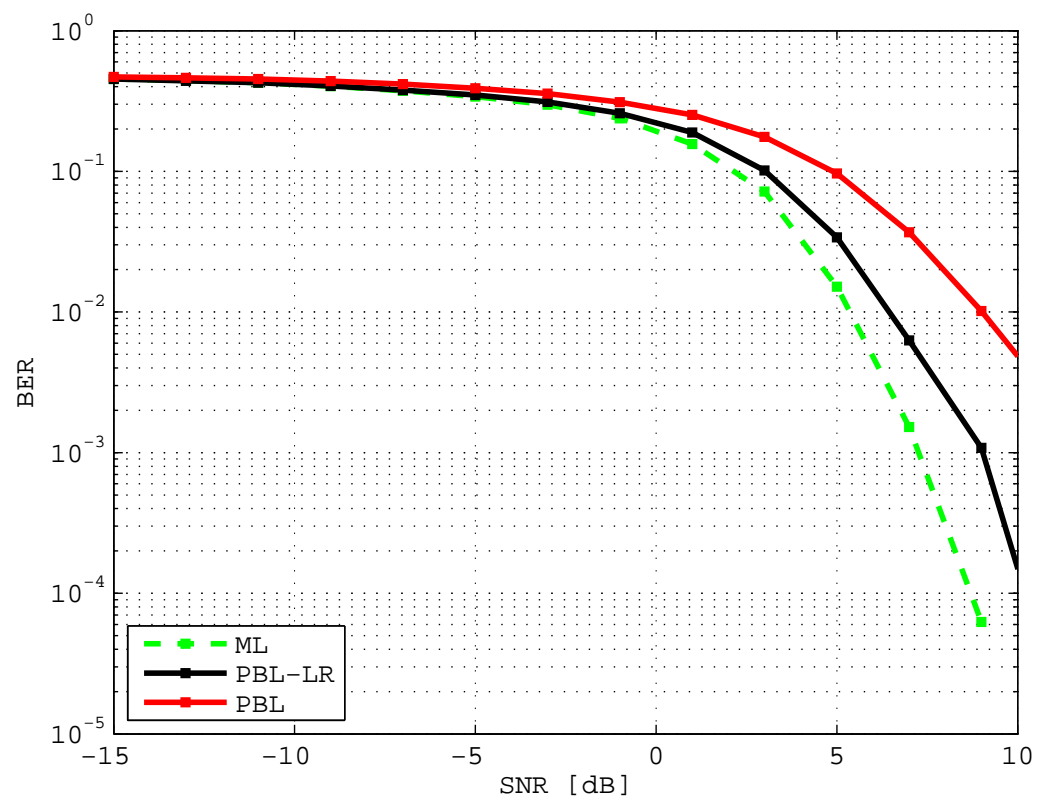

Figura 4.2: Desempenho dos detectores ML, Project Based List e Project Based List com redução de reticulado para 4 usuários com modulação espacial $\left(N_{t_{n}}=4, N_{a}=2, N_{r}=16\right)$. 


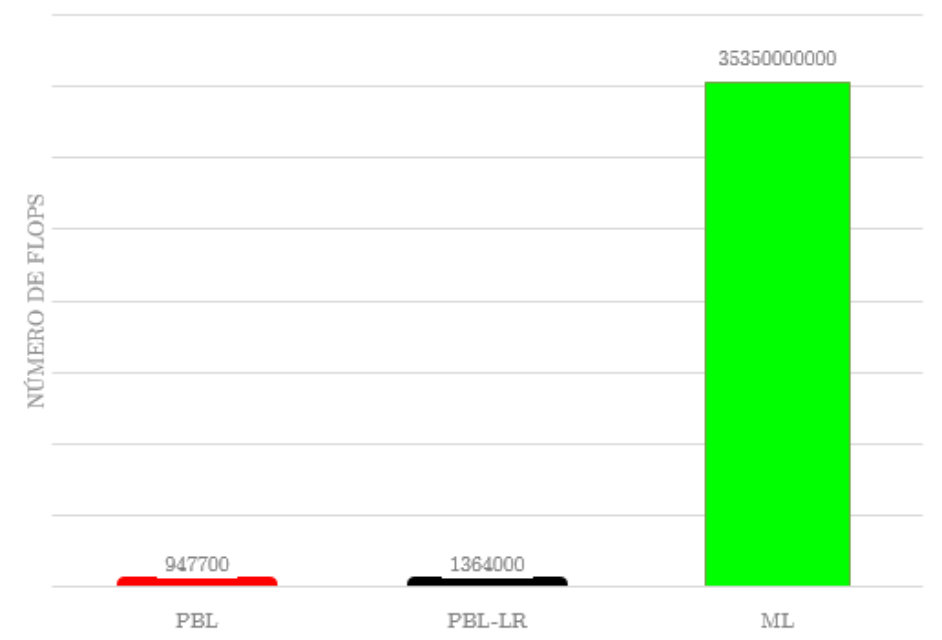

Figura 4.3: Complexidade computacional dos detectores ML, Project Based List e Project Based List com redução de reticulado para 4 usuários com modulação espacial $\left(N_{t_{n}}=4, N_{a}=2, N_{r}=16\right)$.

\subsubsection{Classes de 1 usuário:}

Os resultados a seguir consideram as técnicas de desacoplamento. Dois cenários são considerados, o primeiro com desacoplamento de 4 classes de um usuário e o segundo com 2 classes de 2 usuários.

O primeiro cenário de desacoplamento é apresentado na Figura 4.4. Para o cenário proposto são avaliadas cada uma das técnicas de desacoplamento apresentadas no Capítulo 3. Uma vez feito o desacoplamento, a detecção é feita empregando o detector ML e o detector Project Based List com redução de reticulado para as técnicas DSD e SVD e o detector ML para a técnica ZF-ML.

Na Figura 4.5 pode-se observar como o melhor desempenho é obtido pela detecção sem desacoplamento com os detectores Project Based List com e sem redução de reticulado. O desempenho do detector ML é melhor que o do Project Based List para as técnicas de desacoplamento. Outro aspecto observado é que o desempenho do desacoplamento DSD é melhor que o desempenho da técnica SVD. Um aspecto importante a ser ressaltado é que a técnica ZF-ML tem o mesmo desempenho do detector da técnica SVD-ML.

En termos de complexidade computacional pode-se dizer que as técnicas sem desacoplamento requerem um maior número de operações de ponto flutuante, isto justifica a utilização do desacoplamento prévio à detecção. Dentre as técnicas de desacoplamento pode-se observar que para este exemplo a técnica SVD requer o menor número de operações em comparação com as outras técnicas e a técnica DSD apresenta o maior número de operações, 


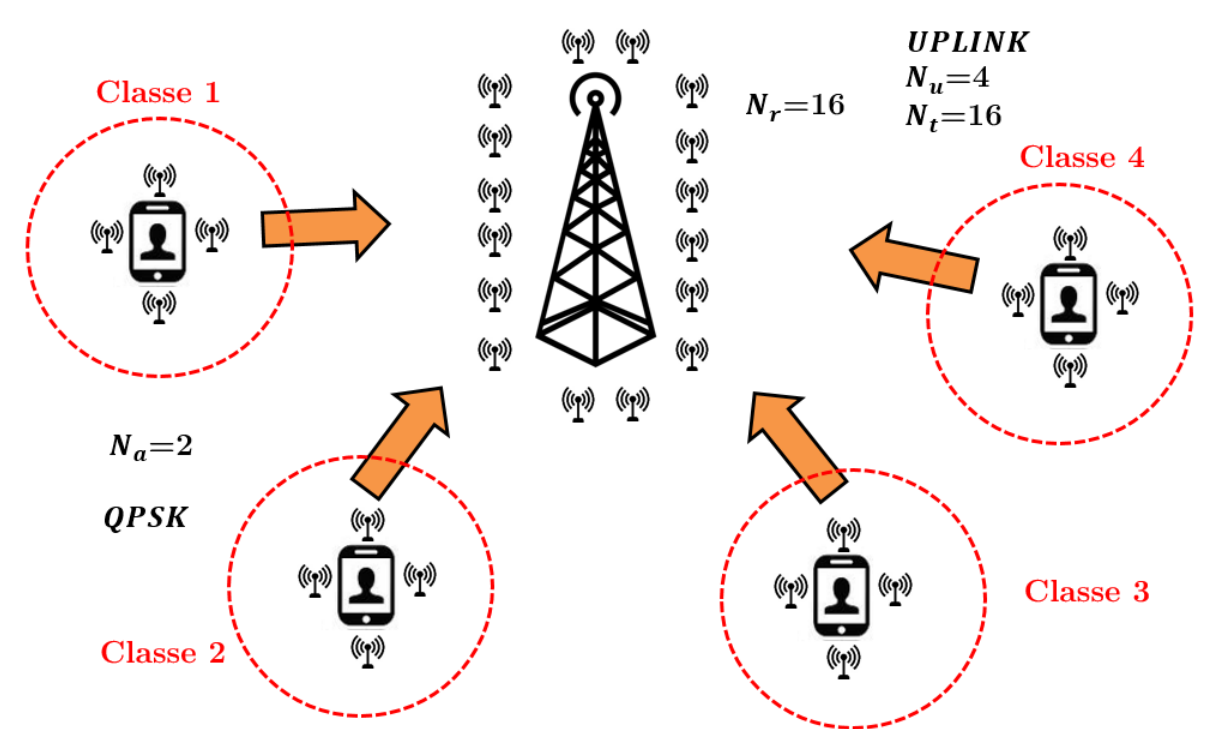

Figura 4.4: Cenário de desacoplamento: 4 classes - 1 usuário por classe.

isto é principalmente ocasionado pela inversão de matriz de canal necessária para o desacoplamento. O detector ZF-ML apresenta uma complexidade um pouco mais alta que o detector SVD-ML, isto é destacável já que o desempenho das duas técnicas é o mesmo. 


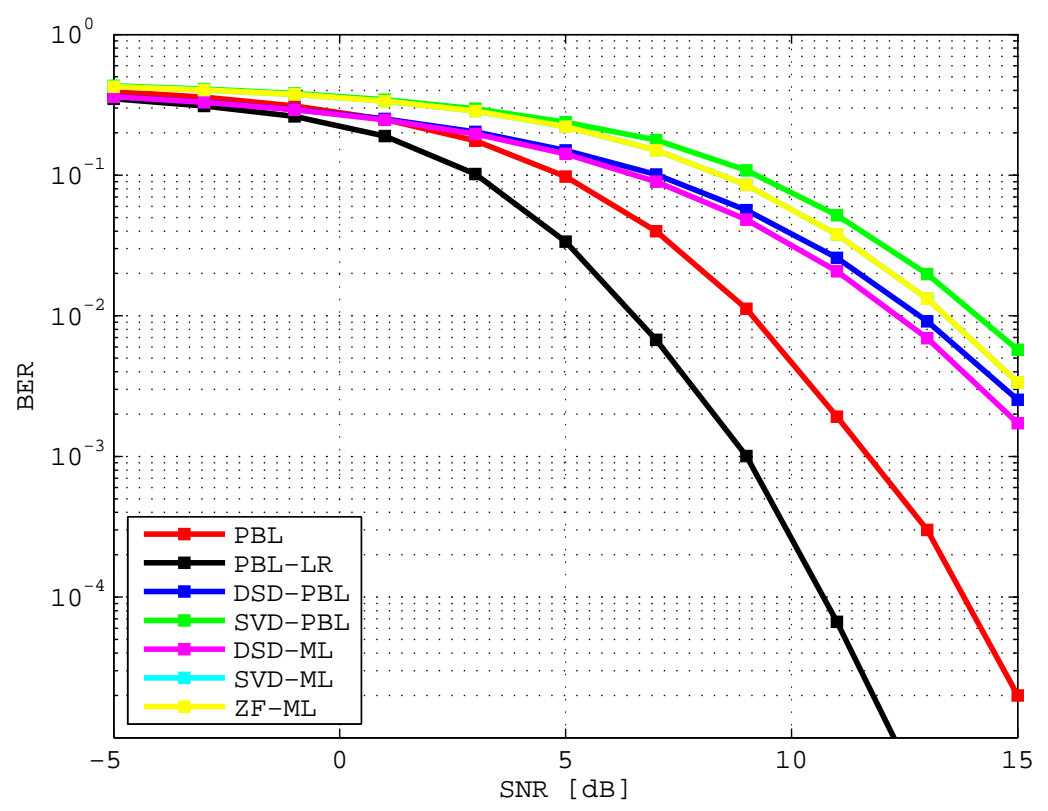

Figura 4.5: Comparação de desempenho das técnicas de desacoplamento estudadas para 4 classes de 1 usuário por classe $\left(N_{t_{n}}=4, N_{a}=2, N_{r}=16\right)$.

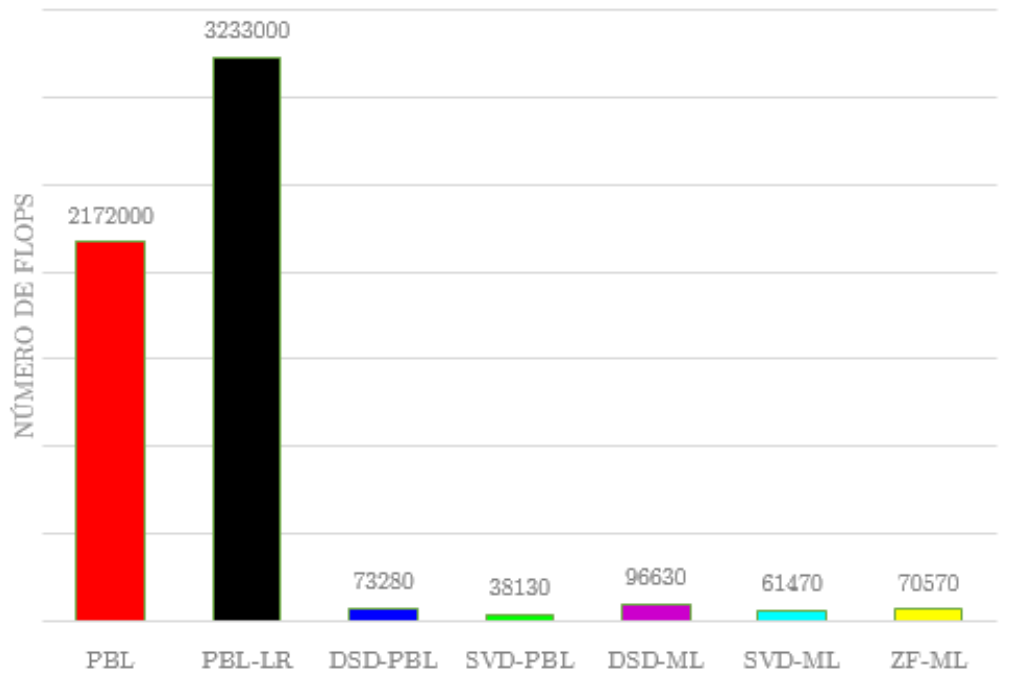

Figura 4.6: Comparação em termos de complexidade computacional das técnicas de desacoplamento estudadas para 4 classes de 1 usuário por classe $\left(N_{t_{n}}=4, N_{a}=2, N_{r}=16\right)$. 


\subsubsection{Classes de 2 usuários:}

O próximo cenário simulado é ilustrado na Figura 4.7. Nele considerase 2 classes com 2 usuários em cada uma.

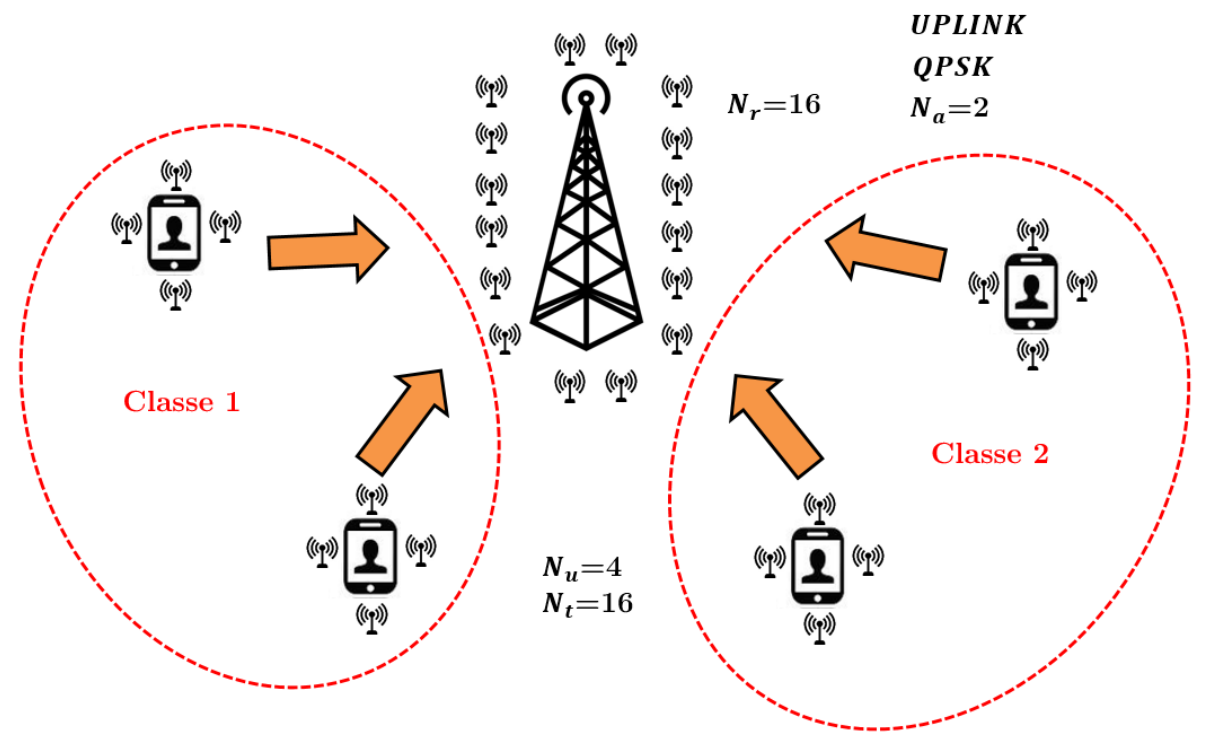

Figura 4.7: Cenário de desacoplamento: 2 classes - 2 usuário por classe.

O desempenho obtido é apresentado na Figura 4.8.Como no presente caso mais usuários são detectados conjuntamente em cada classe o desempenho de todos os detectores sofre uma sensível melhora quando comparado com o cenário da sub-seção 4.1.1. Isto se dá as custas de um aumento de complexidade evidenciado per uma comparação entre as figuras 4.6 e 4.9. É destacável que o detector PBL com redução de latência continua tendo o melhor desempenho, no entanto detectores com desacoplamento conseguem alcançar o desempenho do detector PBL sem LR e sem desacoplamento. Tem-se também que os detectores que empregam a detecção ML depois do desacoplamento têm um melhor desempenho que os detectores que empregam uma detecção PBL depois do mesmo desacoplamento. Comparando os tipos de desacoplamento pode-se dizer que o desempenho da técnica DSD é ligeiramente melhor que o desempenho da técnica SVD e que a técnica SVD-ML continua tendo igual desempenho que a técnica ZF-ML.

Com relação a complexidade computacional para o cenário $2 \times 2$. Podese dizer que os detectores que empregam desacoplamento DSD precisam de um maior número de operações de ponto flutuante, complexidade similar à ocasionada pelo detector ZF-ML. Os detectores com desacoplamento SVD prévio precisam de um menor número de operações em comparação com os detectores sem um desacoplamento feito previamente. Na Figura 4.9 pode-se 


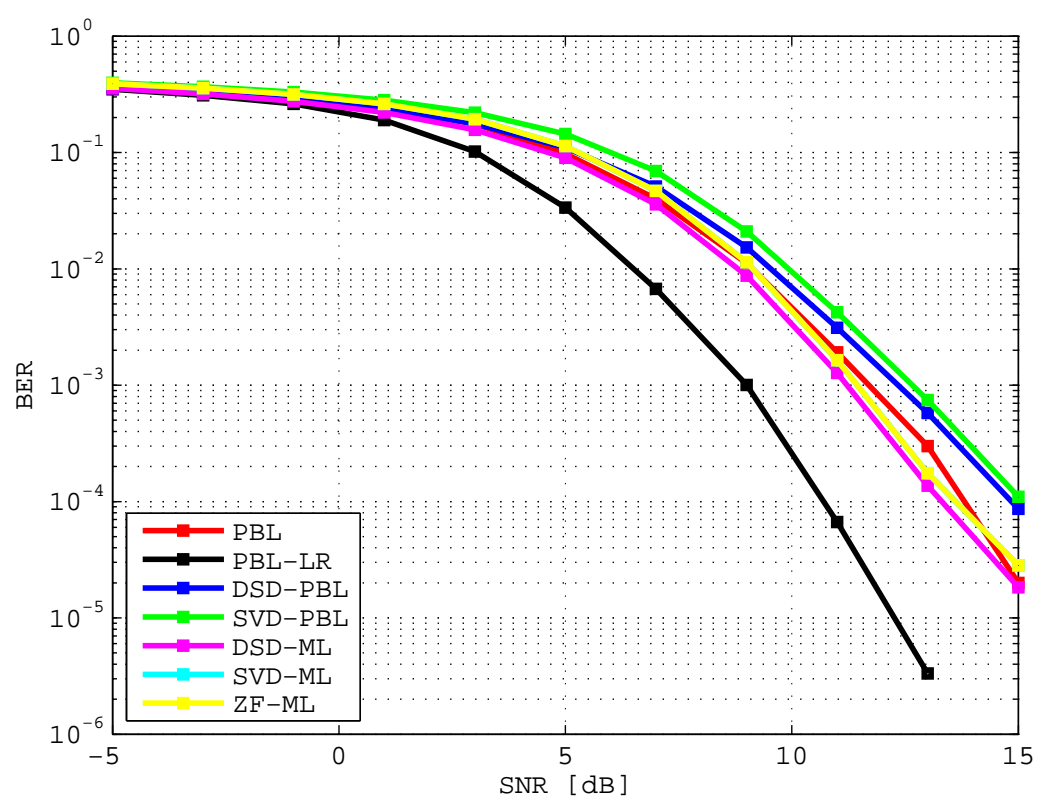

Figura 4.8: Comparação de desempenho das técnicas de desacoplamento estudadas para 2 classes com 2 usuários por classe $\left(N_{t_{n}}=4, N_{a}=2\right.$, $\left.N_{r}=16\right)$.

observar que a complexidade do detector DSD-ML é ligeiramente menor que a da detector DSD-PBL, aspecto também observado para o desacoplamento SVD, conforme destacado na mesma figura. 


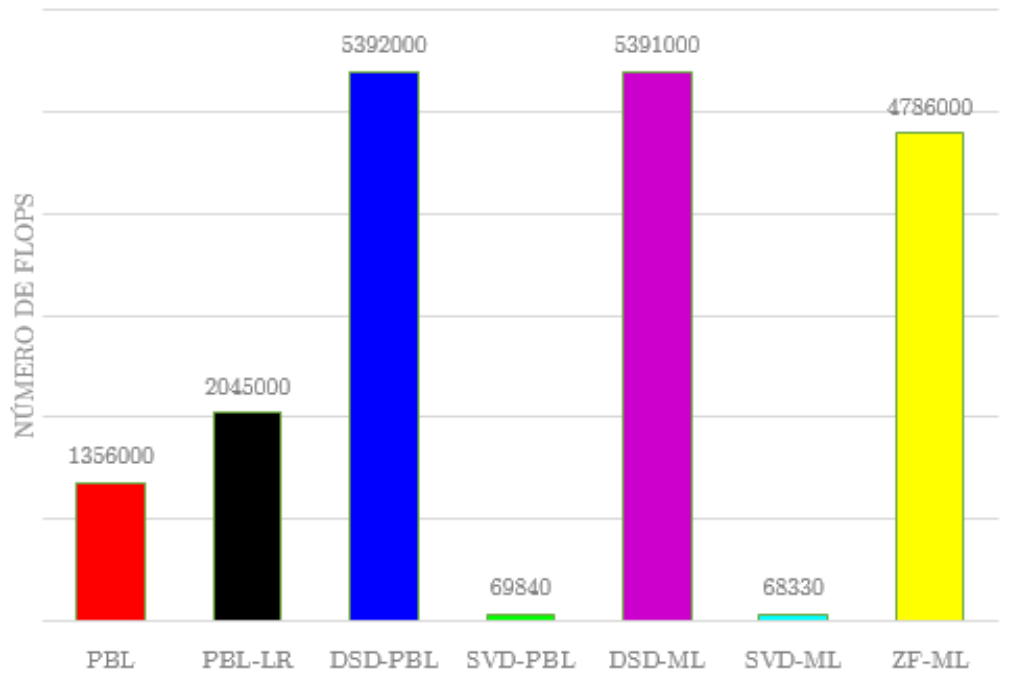

Figura 4.9: Comparação en termos de complexidade computacional das técnicas de desacoplamento estudadas para 2 classes de 2 usuário por classe $\left(N_{t_{n}}=4, N_{a}=2, N_{r}=16\right)$. 


\subsubsection{Efeitos de propagação e correlação}

O desempenho dos cenários apresentados nas Figuras 4.4 e 4.7 é avaliado de uma maneira mais real incluindo efeitos de propagação e correlação. Isto é feito seguindo o cenário de canal descrito em [15].

No cenário é considerado um canal de comunicações $\mathbf{H}_{0_{k}}$ com elementos que podem ser modelados como variáveis aleatórias complexas gaussianas de média zero e variância unitária. Para adicionar os efeitos de correlação é utilizado o modelo de Kronecker para canais de comunicações. Seguindo este modelo a matriz de canal que considera os efeitos de correlação, $\mathbf{G}_{0_{k}} \in \mathbb{C}^{N_{r} \times N_{t_{k}}}$ é dada por:

$$
\mathbf{G}_{0_{k}}=\mathbf{R}_{r_{x}}^{1 / 2} \mathbf{H}_{0_{k}} \mathbf{R}_{t_{x_{k}}}^{1 / 2}
$$

onde $\mathbf{R}_{r_{x}}$ e $\mathbf{R}_{t_{x_{k}}}$ representam a matriz de correlação entre as antenas na recepção na estação radio base e a matriz de correlação entre as antenas de transmissão no $k$-ésimo usuário, respectivamente. Além disso, em 4-2, o operador $(.)^{1 / 2}$ representa a seguinte relação matricial:

$$
\mathbf{R}=\mathbf{R}^{1 / 2} \mathbf{R}^{1 / 2^{H}}
$$

As matrizes de correlação indicadas anteriormente tem a seguinte forma:

$$
\mathbf{R}=\left[\begin{array}{ccccc}
1 & \rho & \rho^{4} & \ldots & \left.\rho^{\left(N_{a}-1\right.}\right)^{2} \\
\rho & 1 & \rho & \ldots & \vdots \\
\rho^{4} & \rho & 1 & \ldots & \vdots \\
\vdots & \vdots & \vdots & \ddots & \vdots \\
\left.\rho^{\left(N_{a}-1\right.}\right)^{2} & \ldots & \rho^{4} & \rho & 1
\end{array}\right]
$$

onde $N_{a}$ é o número de antenas e $\rho$ é o índice de correlação entre antenas vizinhas.

Finalmente a matriz de canal entre o $k$-ésimo usuário e a estação radio base que considera conjuntamente os efeitos de correlação e propagação, $\mathbf{H}_{k} \in \mathbb{C}^{N_{r} \times N_{t_{k}}}$, é dada por: 


$$
\mathbf{H}_{k}=\beta_{k} \mathbf{G}_{0_{k}}
$$

onde $\beta_{k}$ é uma variável aleatória log-normal dada por:

$$
\beta_{k}=10^{\frac{\sigma_{k} \mathcal{N}_{k}(0,1)}{10}} \text {. }
$$

Na expressão (4-6), $\sigma_{k}$ representa o "shadowing spread lognormal" dado em $\mathrm{dB}$, que nesta dissertação foi fixado em $6 \mathrm{~dB}$, e $\mathcal{N}_{k}(0,1)$ é uma variável aleatória Gaussiana de média zero e variância unitária. Foram testados os dois cenários para diferentes valores de correlação $\rho$.

\subsubsection{Correlação na transmissão}

Primeiramente são introduzidos os efeitos de correlação só na transmissão, isto é:

$$
\mathbf{R}_{r_{x}}^{1 / 2}=\mathbf{I}_{N_{r}}
$$

Tem-se então para a equação (4-2) do modelo de matriz de canal

$$
\mathbf{G}_{0_{k}}=\mathbf{I}_{N_{r}} \mathbf{H}_{0_{k}} \mathbf{R}_{t_{x_{k}}}^{1 / 2}
$$

\section{Caso 1.4 classes de 1 usuário:}

Para o primeiro caso é avaliado o desempenho para diferentes valores de $\rho$. Na Figura 4.10 o valor de $\rho$ é de 0.2 , e os detectores sem desacoplamento obtêm o melhor desempenho. Dentro dos detectores com desacoplamento pode-se dizer que aqueles que empregam a técnica DSD apresentam um melhor desempenho mas são superados ao aumentar o SNR pelos detectores ZF-ML e SVD-ML cujos desempenhos são coincidentes.

Nas figuras $4.11,4.12$ e 4.13 os valores de $\rho$ são respectivamente $0.4,0.6$ e 0.8. Nas figuras pode-se observar que para valores altos de $\rho$ os detectores com desacoplamento tendem a alcançar e finalmente superar o desempenho do detector PBL sem LR e desacoplamento. 


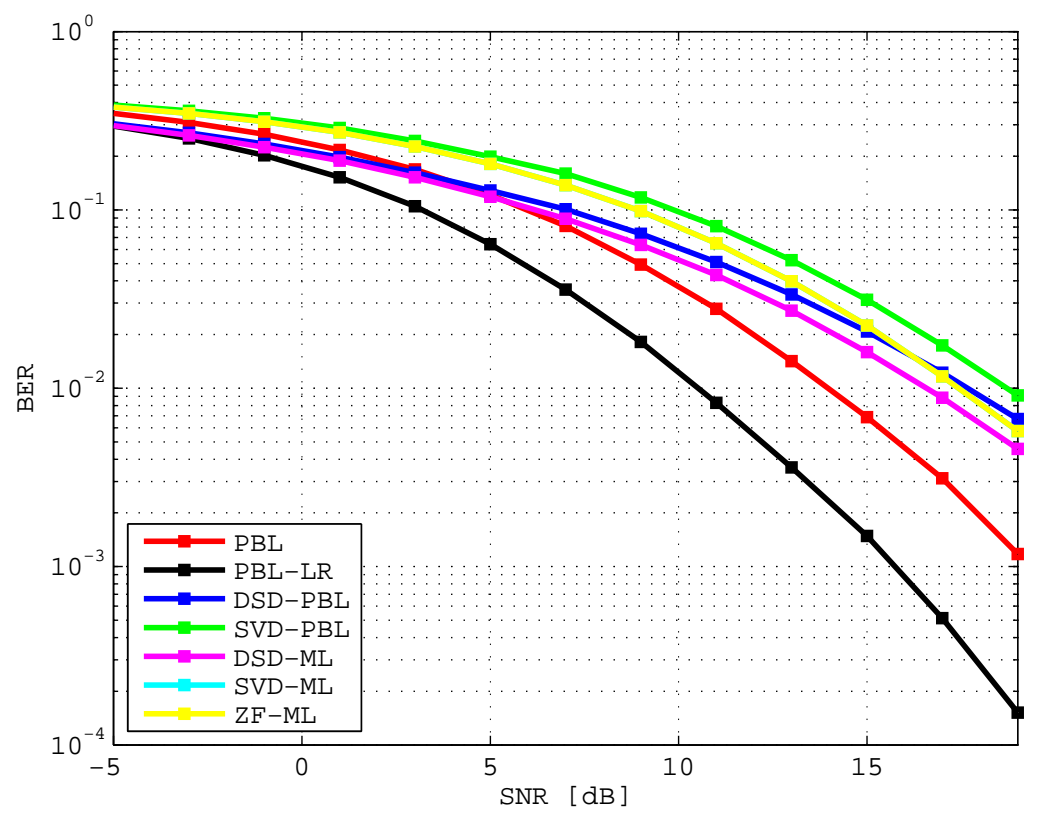

Figura 4.10: Desempenho das técnicas de desacoplamento para 4 classes de 1 usuário com efeitos de propagação e de correlação só na transmissão para um coeficiente $\rho=0,2\left(N_{t_{n}}=4, N_{a}=2, N_{r}=16\right)$.

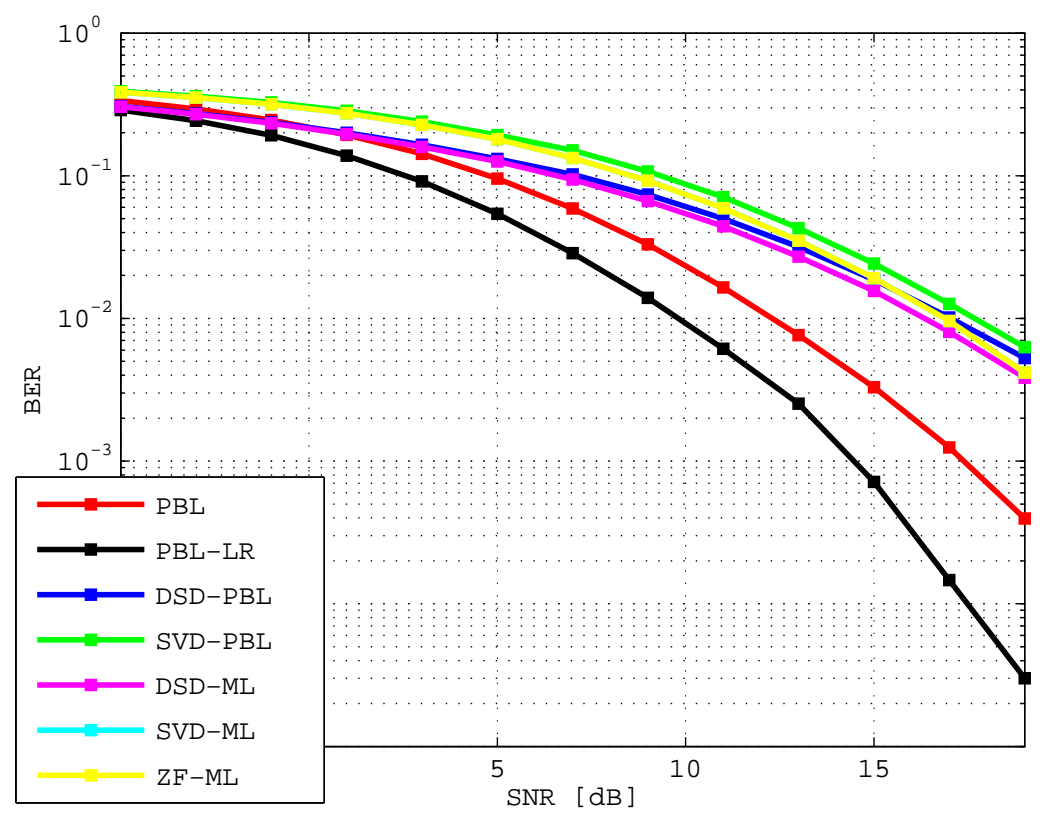

Figura 4.11: Desempenho das técnicas de desacoplamento para 4 classes de 1 usuário com efeitos de propagação e de correlação só na transmissão para um coeficiente $\rho=0,4\left(N_{t_{n}}=4, N_{a}=2, N_{r}=16\right)$. 


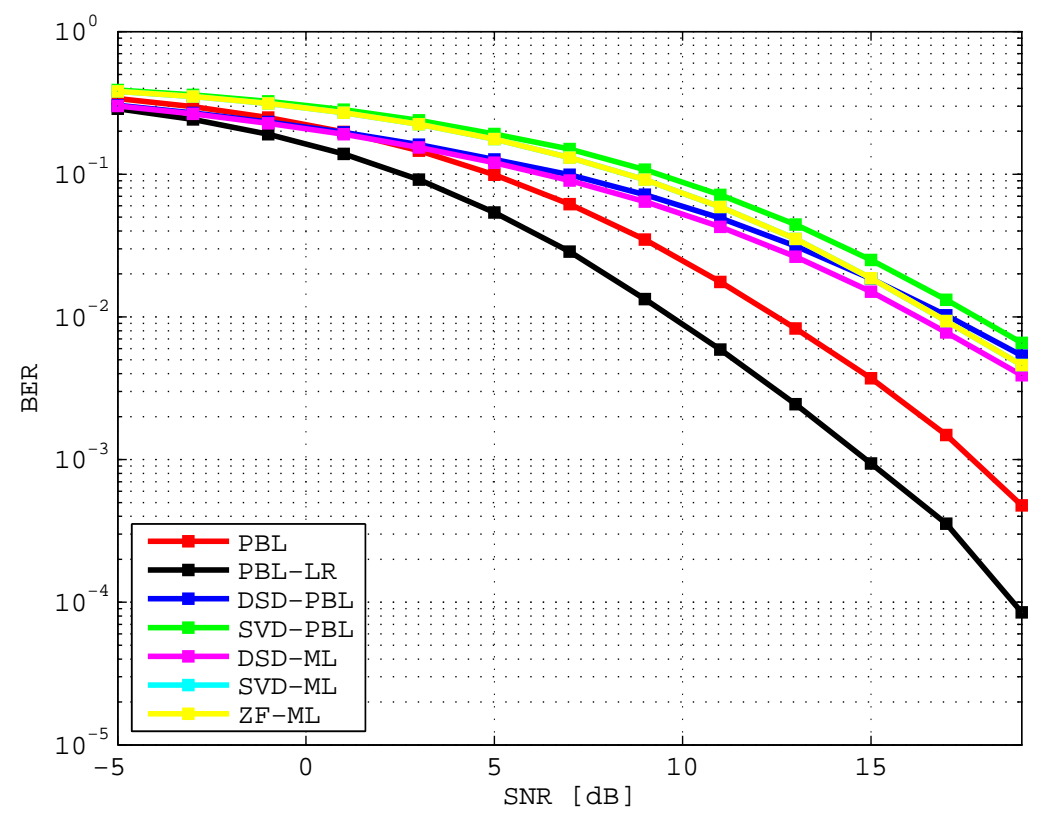

Figura 4.12: Desempenho das técnicas de desacoplamento para 4 classes de 1 usuário com efeitos de propagação e de correlação só na transmissão para um coeficiente $\rho=0,6\left(N_{t_{n}}=4, N_{a}=2, N_{r}=16\right)$.

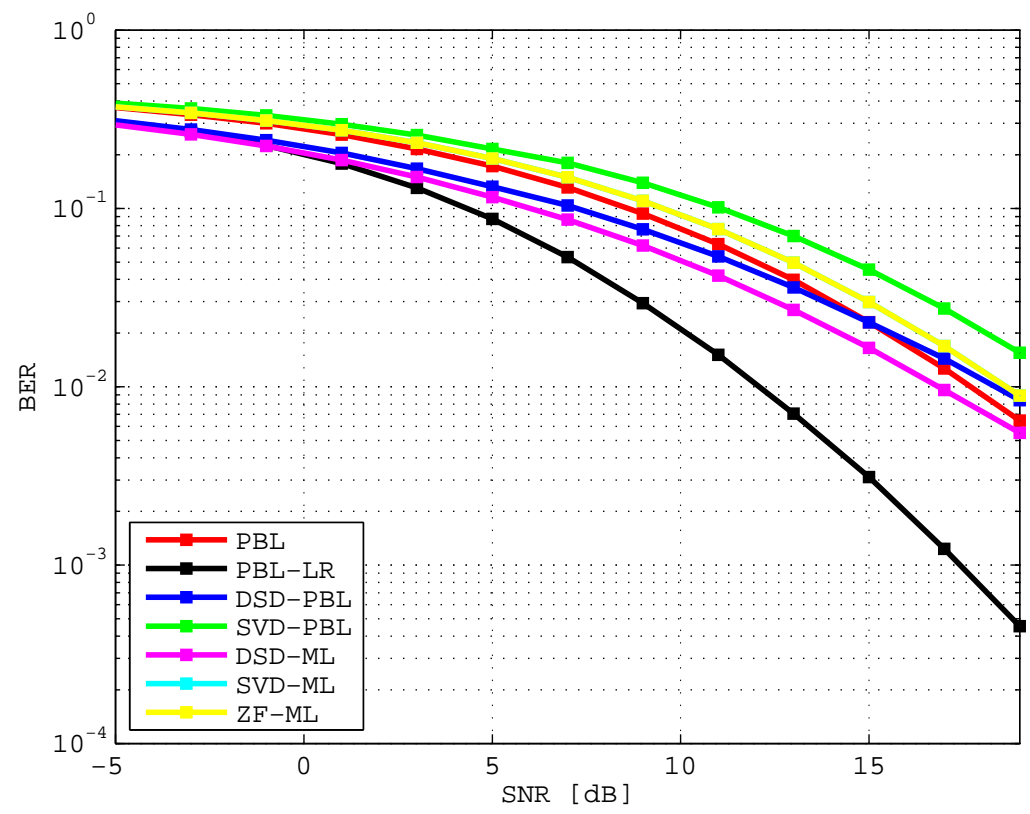

Figura 4.13: Desempenho das técnicas de desacoplamento para 4 classes de 1 usuário com efeitos de propagação e de correlação só na transmissão para um coeficiente $\rho=0,8\left(N_{t_{n}}=4, N_{a}=2, N_{r}=16\right)$. 


\section{Caso 2. 2 classes de 2 usuários:}

O cenário do caso 2 é avaliado também para os mesmos valores de coeficiente de correlação do caso 1 . Na Figura 4.14 para o coeficiente de 0.2 podese notar que o desempenho dos detectores com desacoplamento é muito similar ao detector PBL sem redução de reticulado e sem desacoplamento

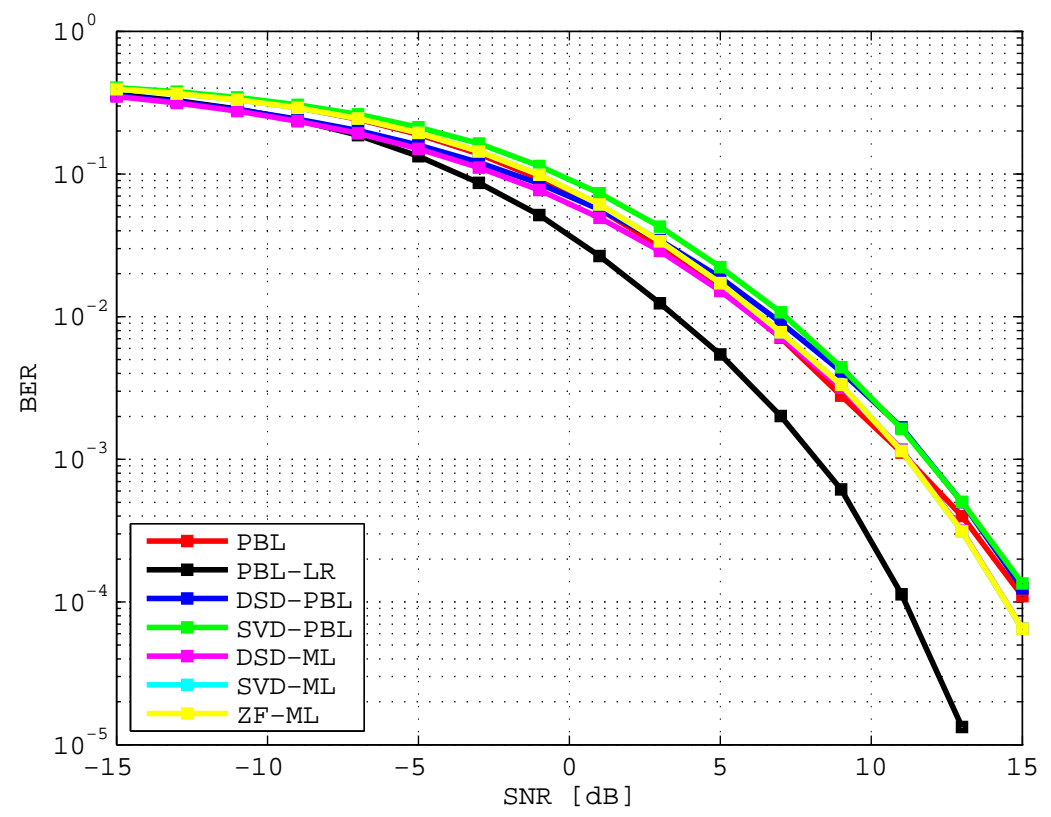

Figura 4.14: Desempenho das técnicas de desacoplamento para 2 classes de 2 usuários com efeitos de propagação e de correlação só na transmissão para um coeficiente $\rho=0,2\left(N_{2} t_{n}=4, N_{a}=2, N_{r}=16\right)$.

Nas Figuras 4.15, 4.16 e 4.17 tem-se coeficientes de correlação de 0.4, 0.6 e 0.8 respectivamente, as figuras permitem notar como o desempenho dos detectores com desacoplamento tendem a superar o desempenho do detector PBL sem redução de reticulado, aspecto que permite justificar a utilização do desacoplamento na detecção de sinais. 


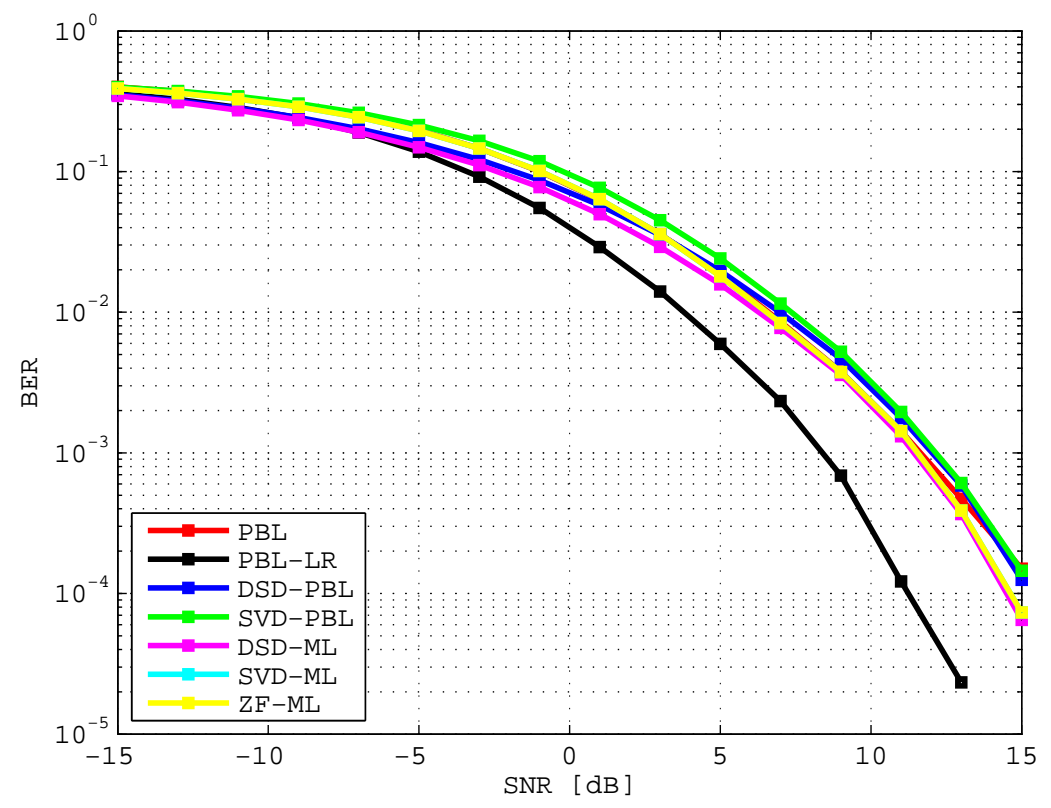

Figura 4.15: Desempenho das técnicas de desacoplamento para 2 classes de 2 usuários com efeitos de propagação e de correlação só na transmissão para um coeficiente $\rho=0,4\left(N_{t_{n}}=4, N_{a}=2, N_{r}=16\right)$.

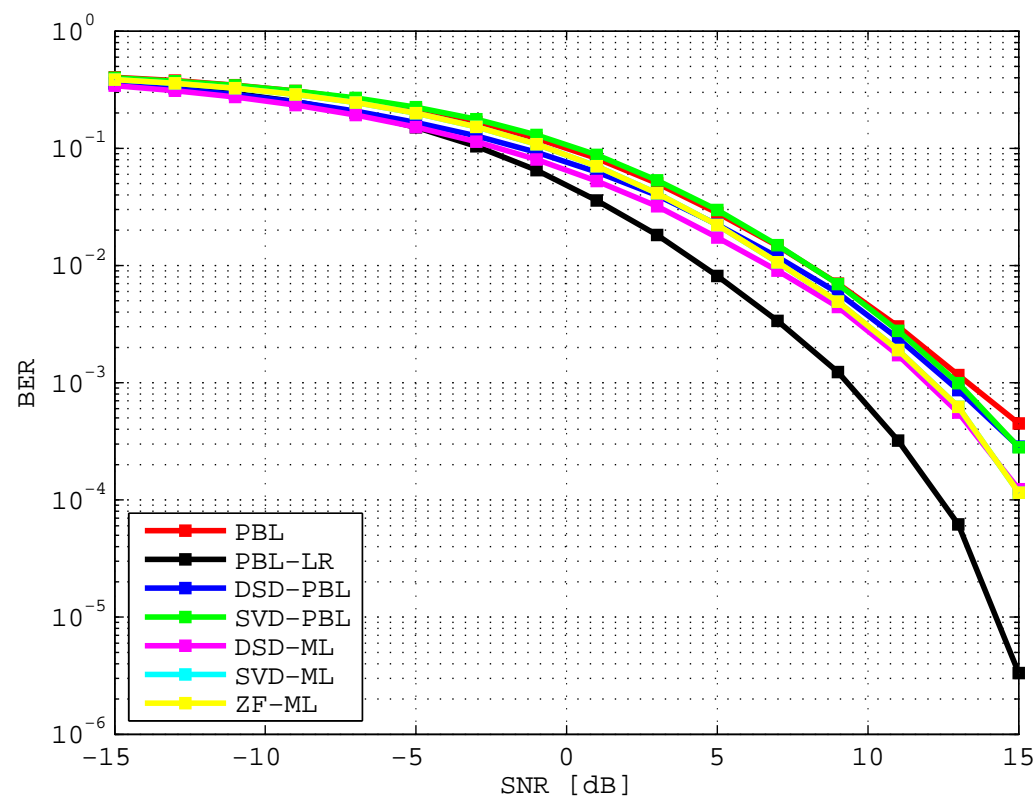

Figura 4.16: Desempenho das técnicas de desacoplamento para 2 classes de 2 usuários com efeitos de propagação e de correlação só na transmissão para um coeficiente $\rho=0,6\left(N_{t_{n}}=4, N_{a}=2, N_{r}=16\right)$. 


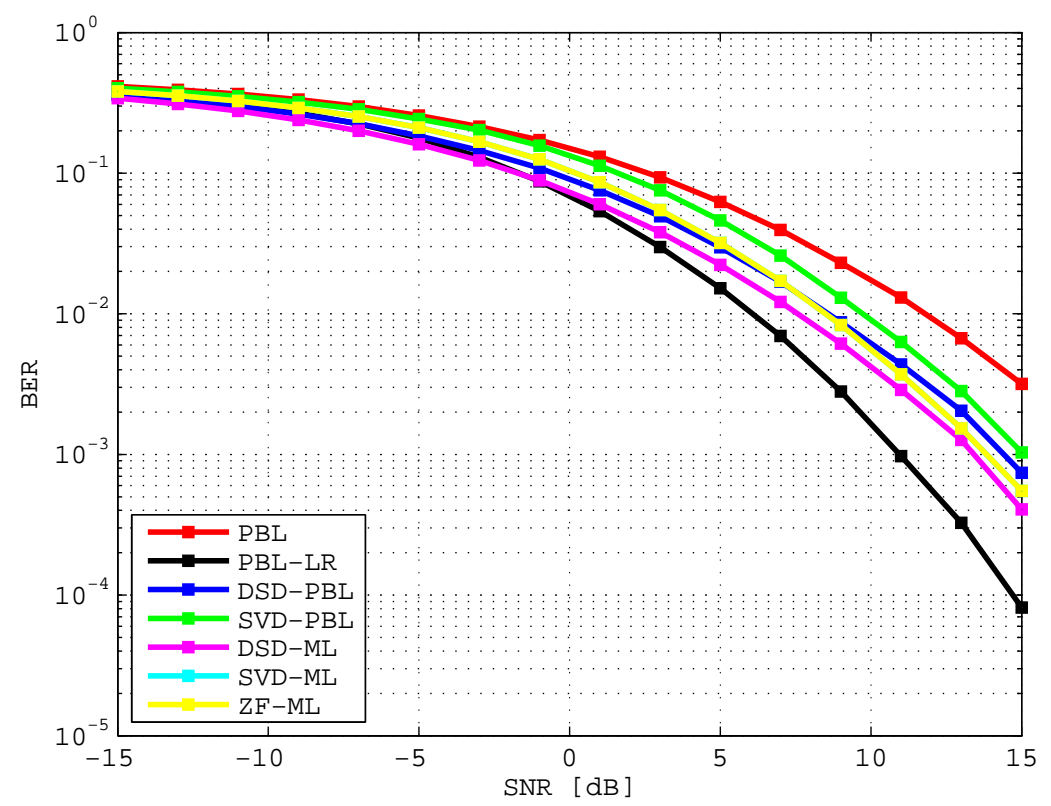

Figura 4.17: Desempenho das técnicas de desacoplamento para 2 classes de 2 usuários com efeitos de propagação e de correlação só na transmissão para um coeficiente $\rho=0,8\left(N_{t_{n}}=4, N_{a}=2, N_{r}=16\right)$. 


\subsubsection{Correlação na transmissão e na recepção}

Os cenários são avaliados incluindo efeitos de correlação na transmissão e na recepção. De maneira similar os cenários são avaliados para diferentes valores de $\rho$.

\section{Caso 1.4 classes de 1 usuário:}

Para o primeiro cenário os valores de coeficientes são os mesmos empregados anteriormente. Na Figura 4.18 tem-se um $\rho$ de 0.2 , a figura permite notar que o desempenho dos detectores com desacoplamento DSD é ligeiramente melhor que o desempenho dos detectores com desacoplamento SVD.

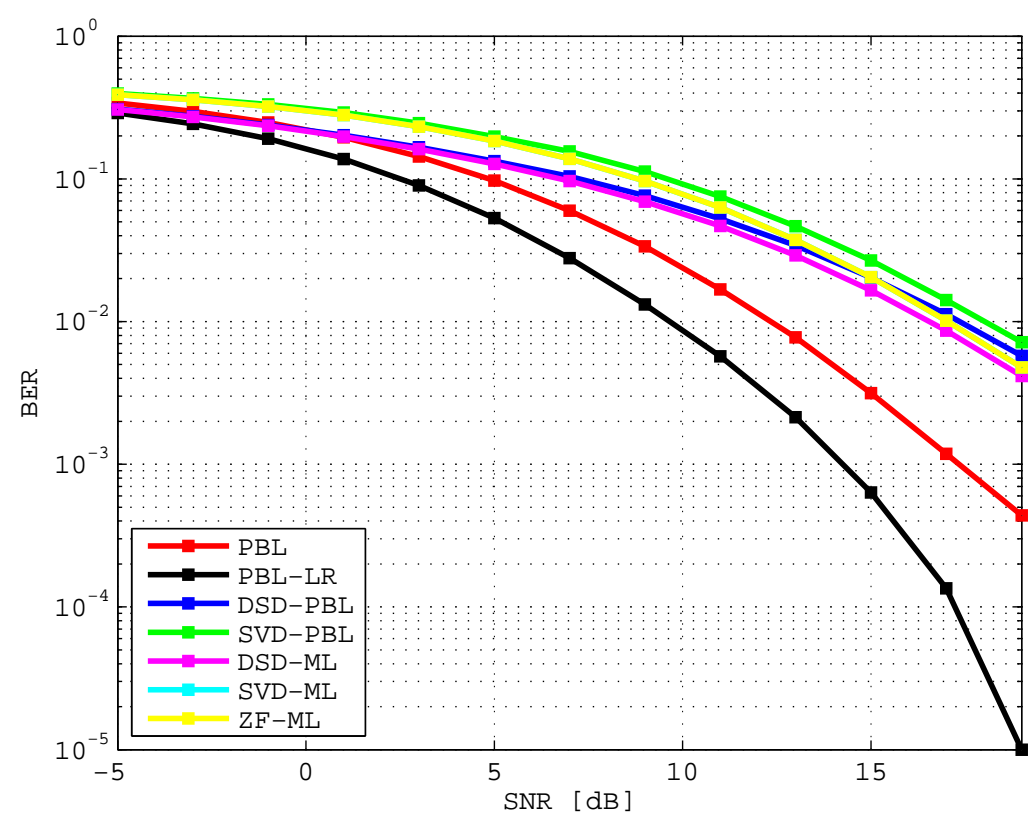

Figura 4.18: Desempenho das técnicas de desacoplamento para 4 classes de 1 usuário com efeitos de propagação e de correlação na transmissão e na recepção para um coeficiente $\rho=0,2\left(N_{t_{n}}=4, N_{a}=2, N_{r}=16\right)$.

As Figuras 4.19, 4.20 e 4.21 com coeficientes 0.4 , 0.6 e 0.8 respectivamente, permitem observar que o desempenho dos detectores com desacoplamento DSD é melhor que o detectores com desacoplamento SVD e que o detector ZF-ML.

A Figura 4.21 permite notar que o desempenho dos detectores com desacoplamento DSD para valores baixos de SNR é melhor que o desempenho do detector PBL sem LR, esta relação se inverte, entretanto, com o aumento da SNR. 


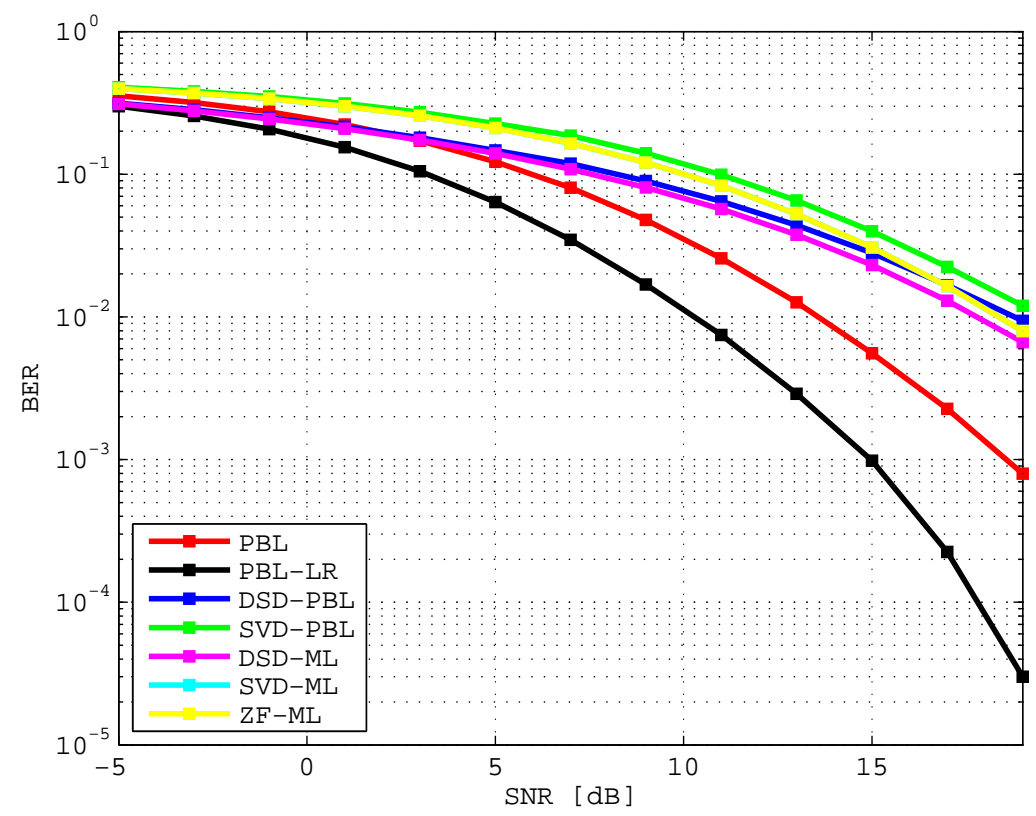

Figura 4.19: Desempenho das técnicas de desacoplamento para 4 classes de 1 usuário com efeitos de propagação e de correlação na transmissão e na recepção para um coeficiente $\rho=0,4\left(N_{t_{n}}=4, N_{a}=2, N_{r}=16\right)$.

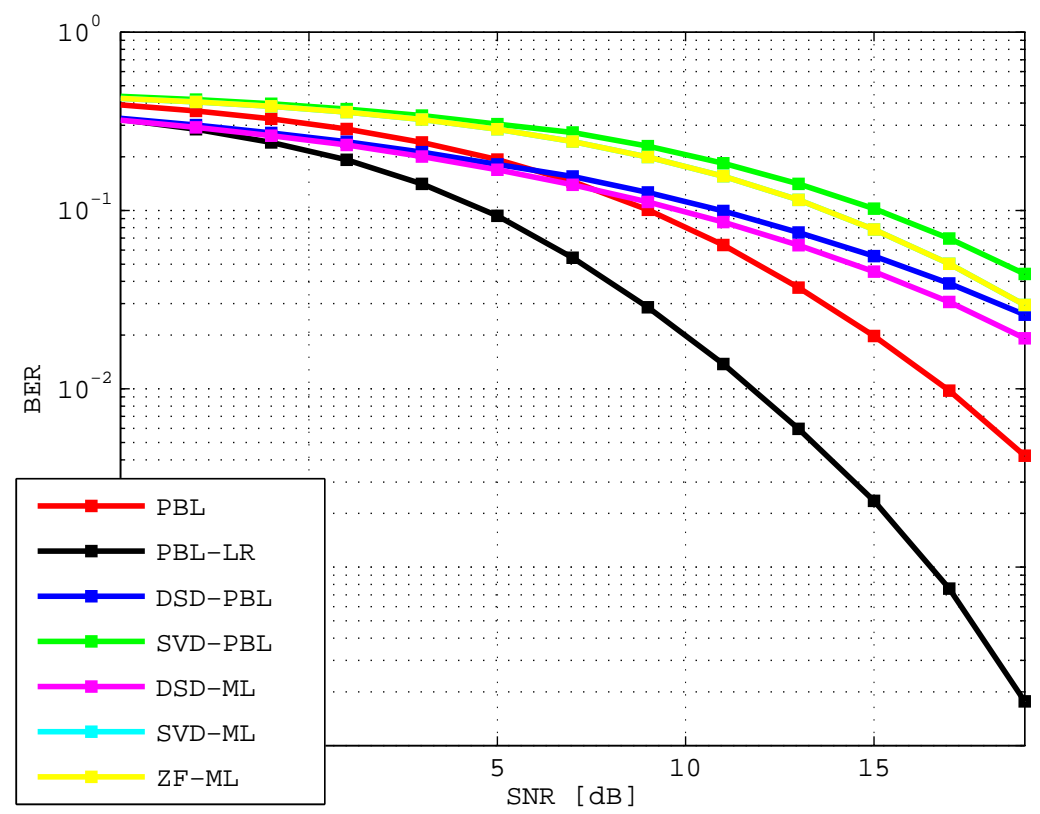

Figura 4.20: Desempenho das técnicas de desacoplamento para 4 classes de 1 usuário com efeitos de propagação e de correlação na transmissão e na recepção para um coeficiente $\rho=0,6\left(N_{t_{n}}=4, N_{a}=2, N_{r}=16\right)$. 


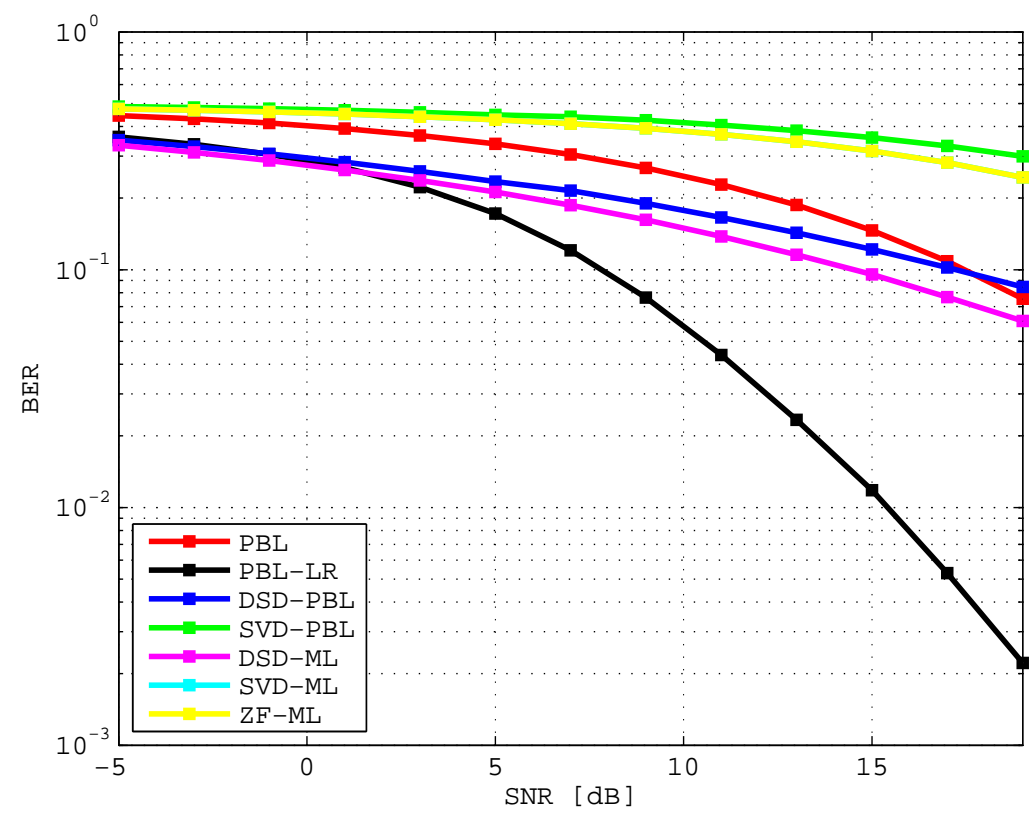

Figura 4.21: Desempenho das técnicas de desacoplamento para 4 classes de 1 usuário com efeitos de propagação e de correlação na transmissão e na recepção para um coeficiente $\rho=0,8\left(N_{t_{n}}=4, N_{a}=2, N_{r}=16\right)$. 


\section{Caso 2. 2 classes de 2 usuários:}

Os efeitos de correlação na transmissão e na recepção são também considerados no cenário de 2 classes com 2 usuários por classe. Na Figura 4.22 pode-se observar que o desempenho dos detectores com desacoplamento é muito similar ao desempenho do detector PBL sem LR, efeito que pode ser gerado pelo fato de que a equalização ZF no caso PBL é feita numa matriz de canal com colunas bem correlacionadas o que torna o "enhanced noise" mais significativo. Em comparação das técnicas de desacoplamento pode-se dizer que o DSD é ligeiramente melhor que o SVD mas o detector SVD-ML e o detector ZF-ML conseguem superar este desempenho ao se-aumentar o valor de SNR.

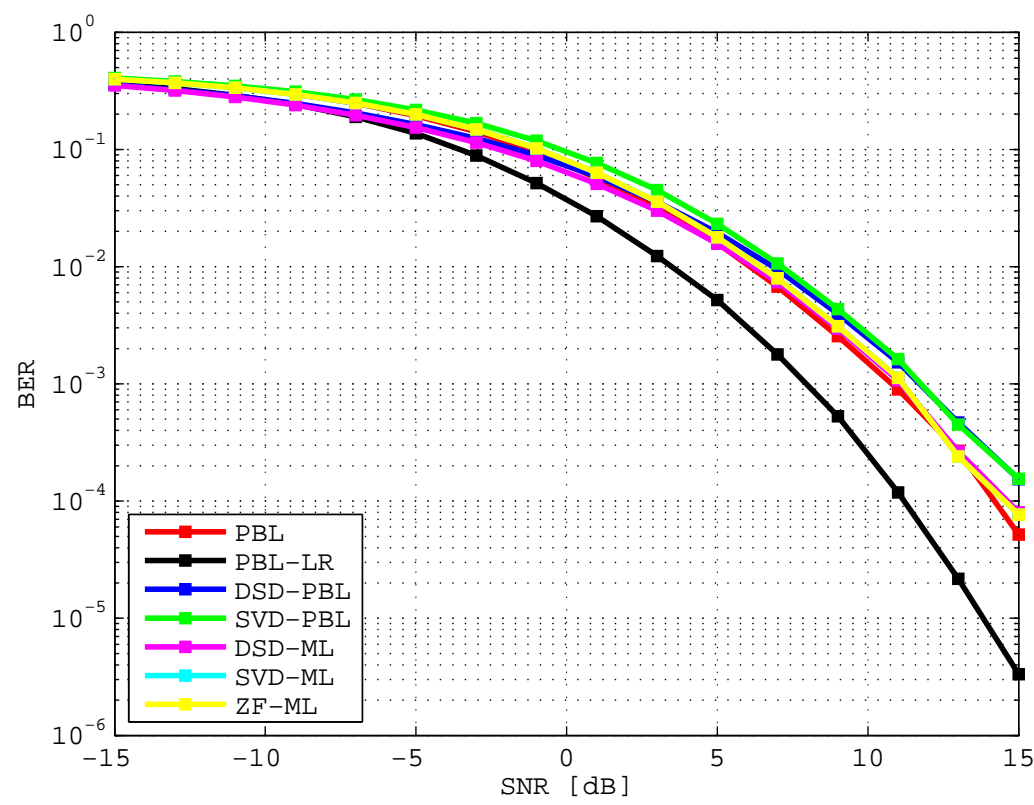

Figura 4.22: Desempenho das técnicas de desacoplamento para 2 classes de 2 usuários com efeitos de propagação e de correlação na transmissão e na recepção para um coeficiente $\rho=0,2\left(N_{t_{n}}=4, N_{a}=2, N_{r}=16\right)$.

As Figuras 4.23 e 4.24 permitem observar que o desempenho do detector PBL sem LR é superado pelos detectores com técnicas de desacoplamento para coeficientes de 0.4 e 0.6 .

Finalmente a Figura 4.25 permite observar que os detectores com desacoplamento DSD apresentam um melhor desempenho que os detectores com desacoplamento SVD mas com o aumento da SNR o desempenho do SVD-ML (e ZF-ML) tendem a superar os desempenhos das técnicas com desacoplamento DSD. 


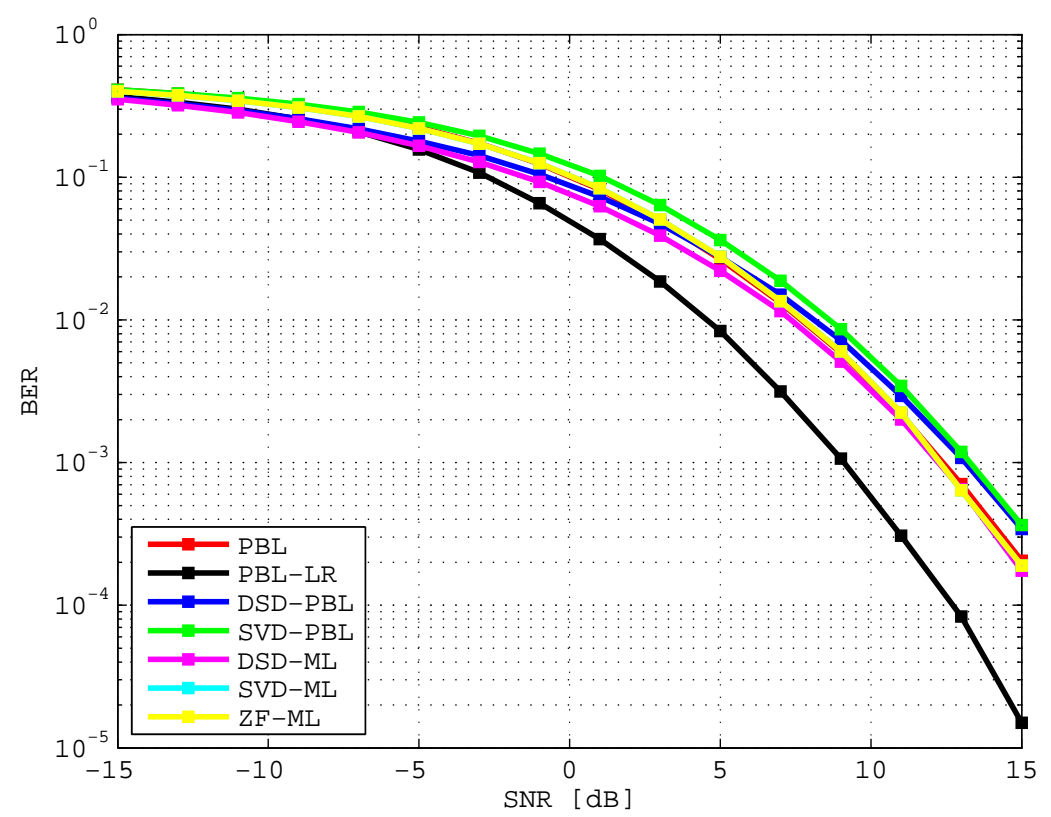

Figura 4.23: Desempenho das técnicas de desacoplamento para 2 classes de 2 usuários com efeitos de propagação e de correlação na transmissão e na recepção para um coeficiente $\rho=0,4\left(N_{t_{n}}=4, N_{a}=2, N_{r}=16\right)$.

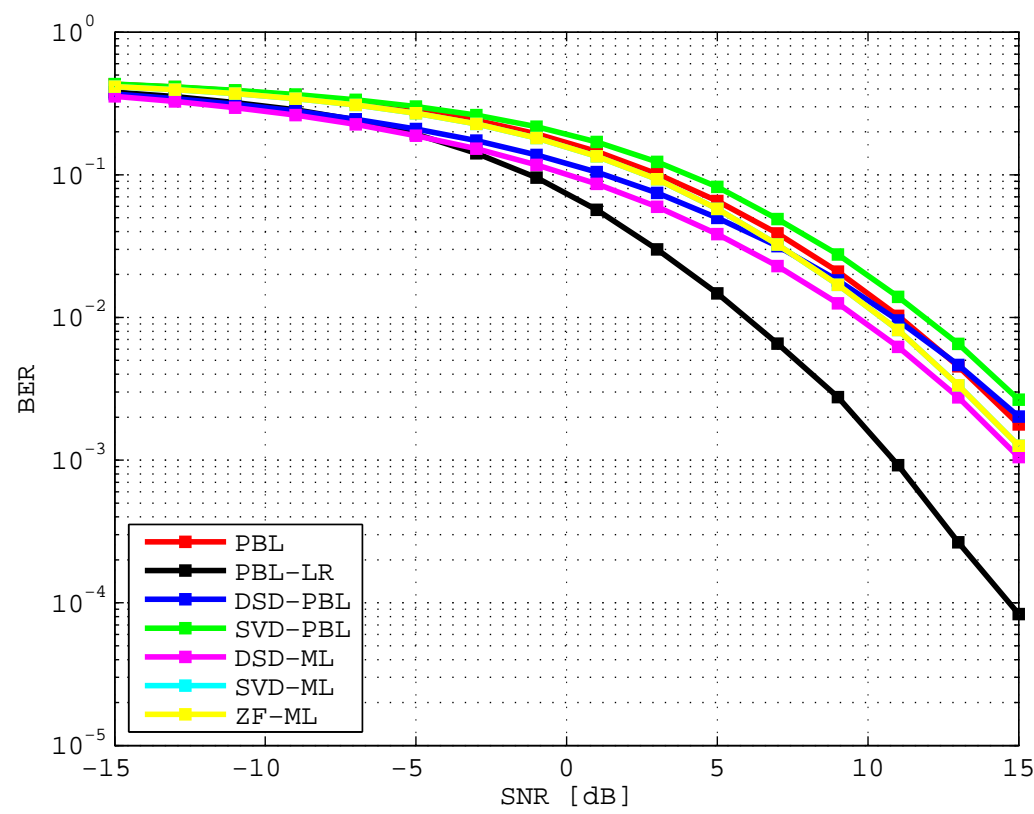

Figura 4.24: Desempenho das técnicas de desacoplamento para 2 classes de 2 usuários com efeitos de propagação e de correlação na transmissão e na recepção para um coeficiente $\rho=0,6\left(N_{t_{n}}=4, N_{a}=2, N_{r}=16\right)$. 


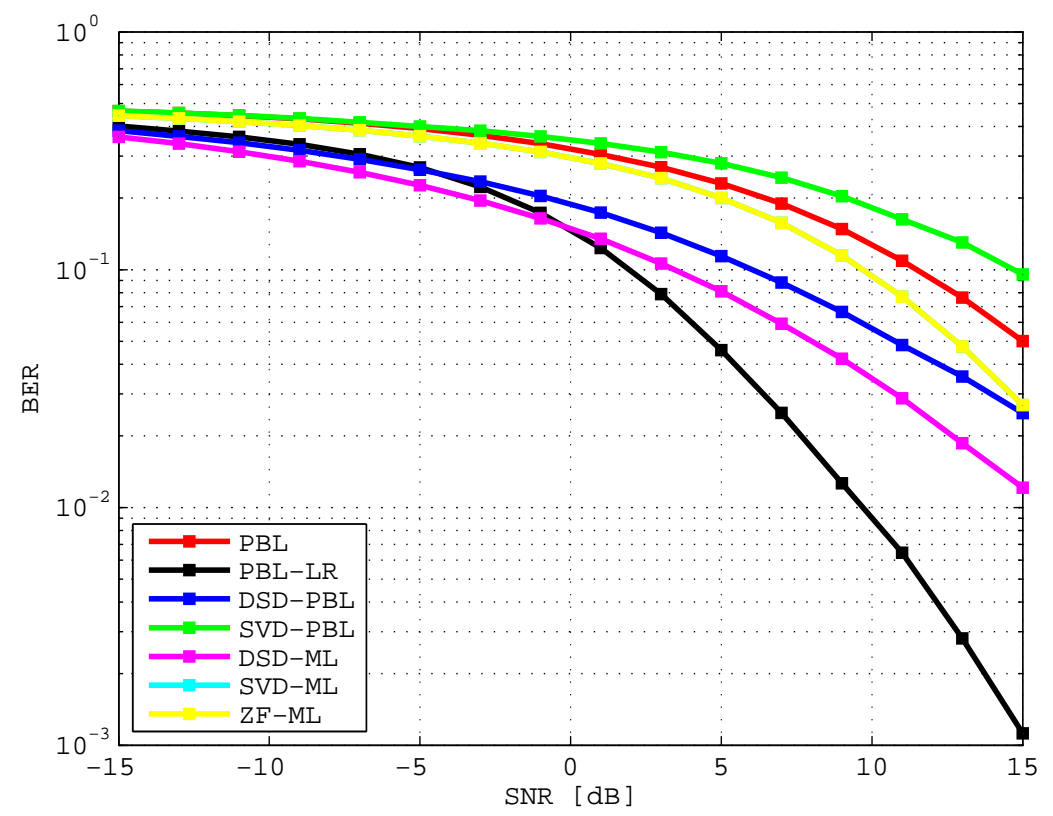

Figura 4.25: Desempenho das técnicas de desacoplamento para 2 classes de 2 usuários com efeitos de propagação e de correlação na transmissão e na recepção para um coeficiente $\rho=0,8\left(N_{t_{n}}=4, N_{a}=2, N_{r}=16\right)$. 


\subsection{Usuários}

Outra simulação feita avalia o desempenho e complexidade de um cenário com 16 usuários, cada um dos quais tem 4 antenas no total mas só 2 ativas na transmissão e transmitem símbolos com modulação QPSK. Na ERB tem-se 64 antenas para a recepção. Os elementos da matriz de canal $\mathbf{H}$ são modelados como variáveis aleatórias estatisticamente independentes Gaussianas complexas circularmente simétricas todas com média zero e variância unitária. Os resultados são apresentados nas Figuras 4.26 e 4.27.

A Figura 4.26 permite observar que o desempenho dos detectores com desacoplamento DSD apresentam um desempenho melhor que os detectores com desacoplamento SVD. Os detectores que empregam uma detecção ML depois do desacoplamento obtêm um melhor desempenho do que aqueles que empregam detecção PBL.

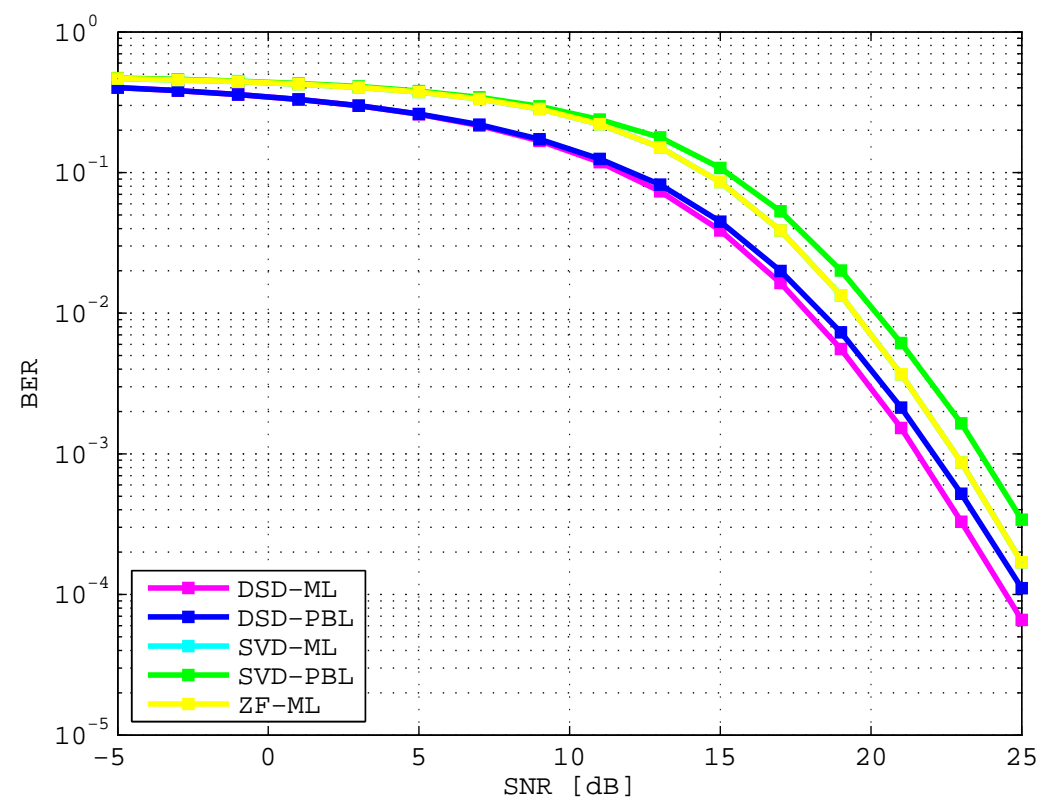

Figura 4.26: Desempenho das técnicas de desacoplamento para 16 classes de 1 usuário $\left(N_{t_{n}}=4, N_{a}=2, N_{t}=N_{r}=64\right)$.

Observa-se que apesar de desempenhos idênticos o ZF-ML tem complexidade bastante inferior ao SVD-ML. Vantagem que se acentua em sistemas com maior escala e número de usuários. 


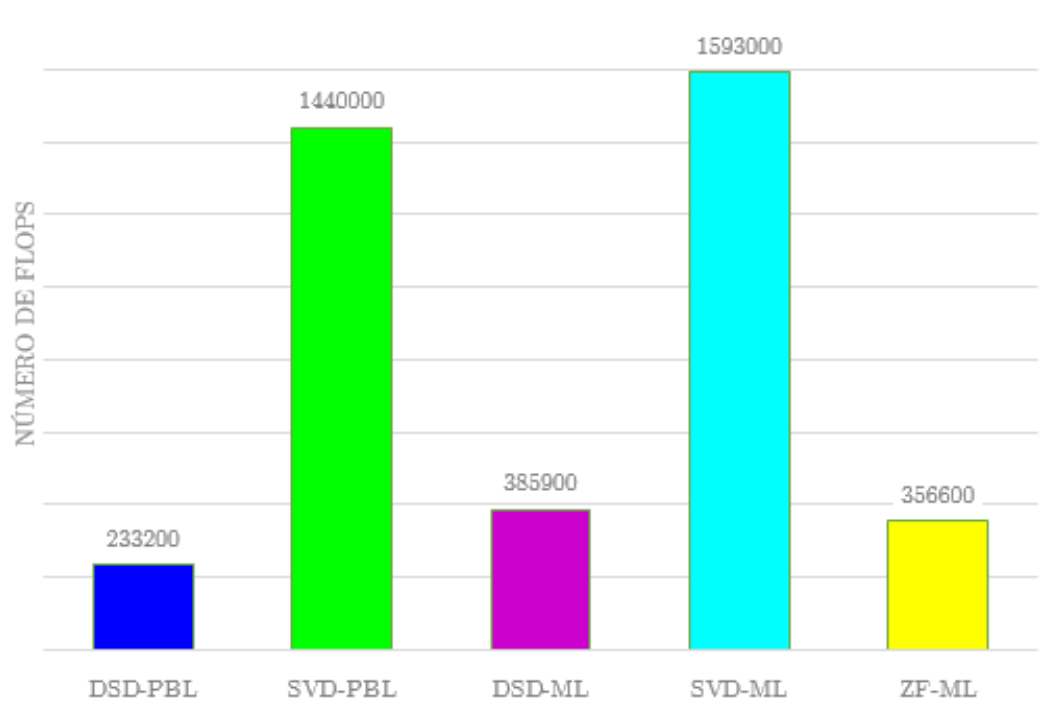

Figura 4.27: Complexidade computacional das técnicas de desacoplamento para 16 classes de 1 usuário. 


\subsection{Usuários}

Finalmente a ultima simulação feita avalia o desempenho de um cenário com 3 usuários, os quais tem as mesmas características do cenário anterior. Na ERB o número de antenas para a recepção é 16, isto significa que a matriz de canal $\mathbf{H}$ não é quadrada. $\mathrm{O}$ resultado é apresentado na Figura 4.28 , na qual pode-se observar que o desempenho dos detectores ZF-ML e SVD-ML continua sendo o mesmo, indiferentemente de que a matriz $\mathbf{H}$ não seja quadrada.

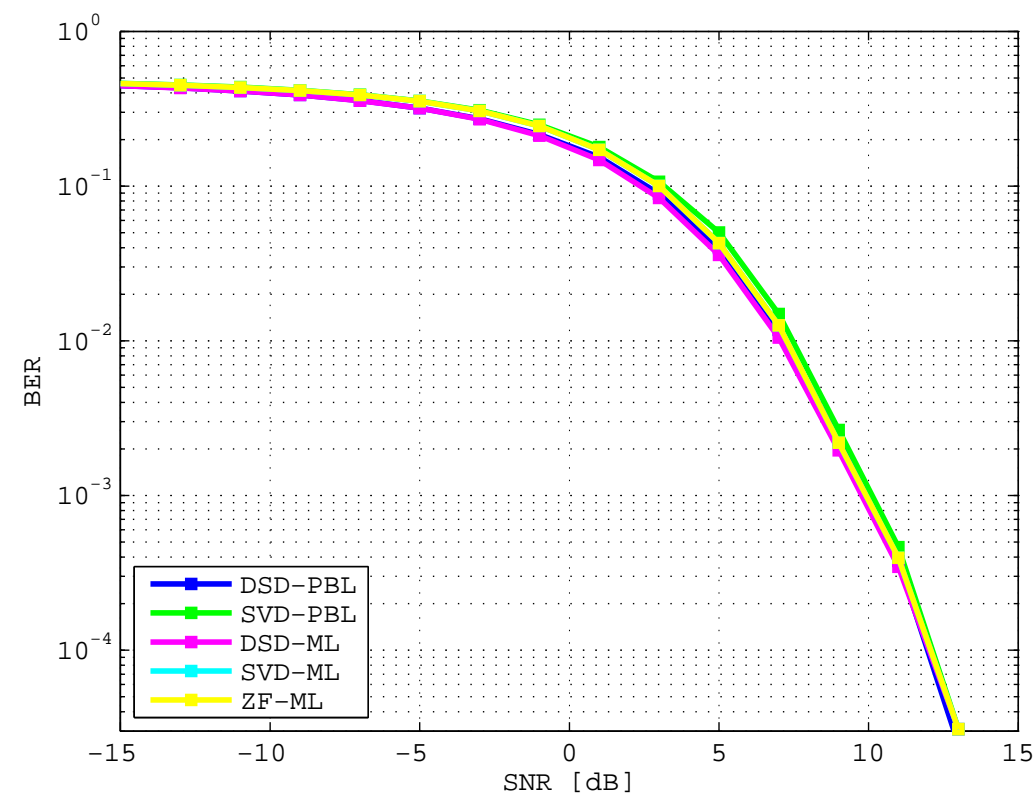

Figura 4.28: Desempenho das técnicas de desacoplamento para 3 classes de 1 usuário $\left(N_{t_{n}}=4, N_{a}=2, N_{t}=12, N_{r}=16\right)$. 


\section{Conclusões}

O trabalho desenvolvido nesta dissertação de mestrado foi focado na combinação de dois conceitos de sistemas de comunicações: a Modulação Espacial (Capítulo 2) e a Detecção Desacoplada de Sinais (Capítulo 3).

A Modulação espacial, seus fundamentos e as técnicas de detecção empregadas para este conceito foram estudadas. O estudo dos detectores incluiu o detector Maximum Likelihood (ML) e o detector Project Based List(PBL), especializados para a detecção de sinais com modulação espacial.

Técnicas de desacoplamento de sinais em enlace reverso para sistemas SM-MIMO foram apresentadas no Capítulo 3. A topologia do sistema e as técnicas DSD, SVD foram apresentadas e a técnica ZF-ML foi proposta como uma alternativa a estas duas técnicas.

A avaliação do desempenho e complexidade (Capítulo 4) contemplou resultados para diferentes cenários de simulação com 4 usuários utilizando modulação espacial, cada um com 4 antenas na transmissão das quais duas são ativadas por transmissão, modulação QPSK e 16 antenas receptoras na estação radio base. Como era esperado o resultado de desempenho em termos da taxa de erro de bit do detector ML sem desacoplamento nenhum é o melhor seguido dos detectores Project Based List com e sem redução de reticulado, mas a complexidade computacional do detector ML é muito elevado tornando sua utilização impraticável em sistemas de larga escala. $O$ primeiro cenário de 4 classes de 1 usuário e o segundo cenário constituído de 2 classes de 2 usuários foram utilizados para a avaliação da detecção depois de ser aplicadas as técnicas de detecção do Capítulo 3. Para o primeiro cenário as técnicas sem desacoplamento tiveram um desempenho sensivelmente melhor em termos da taxa de erro de bit mas com complexidade muito maior em comparação com as técnicas com desacoplamento. Para o segundo cenário os detectores com desacoplamento alcançaram o desempenho da técnica PBL sem redução de reticulado e sem desacoplamento, os detectores com desacoplamento SVD apresentam menor complexidade no entanto seu desempenho em termos da BER se mostrou ligeiramente inferior ao dos detectores com desacoplamento DSD.

Os dois cenários apresentados foram avaliados de uma maneira mais 
realista incluindo efeitos de propagação e correlação. O modelo de Kronecker foi escolhido na dissertação e a avaliação foi feita para diferentes valores do indice de correlação $\rho$. Inicialmente foram incluídos efeitos de propagação e os efeitos de correlação apenas na transmissão. Para os dois cenários os resultados indicaram que as técnicas de detecção com desacoplamento conseguem alcançar e superar o desempenho do detector PBL sem LR, justificando a utilização do desacoplamento na detecção de sinais.

A comparação entre as técnicas que empregam desacoplamento permite concluir que para valores não muito altos de SNR o desacoplamento DSD é o que apresenta melhor desempenho, tal desempenho é, entretanto, superado pelos detectores que utilizam desacoplamento SVD quando o valor da SNR aumenta.

Um aspecto que se observou foi que o desempenho do detector ZF-ML em termos da taxa de erro de bit é idêntico ao desempenho do detector SVDML.

As técnicas de desacoplamento foram avaliadas para um número maior de usuários, 16 usuários cada um com as mesmas características dos cenários anteriores, 4 antenas na transmissão, 2 ativas, modulação QPSK e 64 antenas na recepção. A simulação permitiu observar que o desempenho dos detectores com desacoplamento DSD manteve-se melhor que o dos detectores com desacoplamento SVD para um número grande de usuários. Em termos da complexidade os detectores DSD mostraram-se menos complexos que os detectores SVD. Observa-se também que apesar de, como já foi mencionado anteriormente o detector ZF-ML ter o mesmo desempenho do detector SVD-ML sua complexidade torna-se significativamente menor que a do SVD-ML a medida que o número de usuários/classes aumenta.

Uma última simulação foi feita para 3 usuários com as mesmas características dos usuários simulados anteriormente. O objetivo foi o de avaliar o desempenho dos detectores quando a matriz de canal $\mathbf{H}$ não é quadrada.

Finalmente pode-se concluir que a utilização de técnicas de desacoplamento para a detecção de sinais é uma opção bastante atraente para o enlace reverso de sistemas MIMO de larga escala. O extenso número de usuários e dispositivos inteligentes presentes em todas as atividades na atualidade vão requerer estratégias que permitam garantir uma boa detecção em termos de taxa de erro de bit e complexidade computacional e o desacoplamento dos sinais recebedos na ERB torna-se uma necessidade.

Por outro lado, o uso de modulação espacial permite que os usuários, utilizem um número menor de cadeias de RF no transmissor, com consequente redução de sua complexidade e sem sacrifício de eficiência espectral 
da transmissão Estos fatos tornam importante a continuação e aprofundamento dos estudos que foram objeto desta dissertação. 


\section{Referência bibliográfica}

[1] 5g network technology: Putting europe at the leading edge. 2016. by EUROPEAN PARLIAMENTARY RESEARCH STUDY.

[2] 5 radio access: requirements, concept and technologies. 2014. by NTT DOCOMO INC.

[3] DI RENZO, M; HAAS, H. Spatial modulation for multiple-antenna wireless systems:a survey. IEEE Communications Magazine, 49:182-191, 2011.

[4] MESLEH, R; HAAS, H; SINANOVIC, S; ; AHN, C. W ; YUN, S. Spatial modulation. IEEE Transactions on vehicular technology, 57(4), 2008.

[5] WANG, J; JIA, S ; SONG, J. Generalised spatial modulation system with multiple active transmit antennas and low complexity detection scheme. IEEE Transactions on wireless communications, 11(4), 2012.

[6] CAL BRAZ, J. A. Detecção de sinais em sistemas multiantena com Modulação Espacial. 2015. 140 f. PhD thesis, Tese (Doutorado em Engenharia Eléctrica)-Departamento de Engenharia Eléctrica, Pontificia Universidade Católica do Rio de Janeiro, Rio de Janeiro, 2015.

[7] NARASIMHAN, T; CHOCKALINGAM, A. Large-scale multiuser SMMIMO versus massive MIMO. Information Theory and Applications Workshop (ITA), 2014.

[8] NARAYANAN, S; MARIUM, J ; STAVRIDIS, A. Multiuser spatial modulation mimo. Wireless Communications and Networking Conference (WCNC), 2014.

[9] CAL BRAZ, J. A; SAMPAIO-NETO, R. Projection-based list detection in generalized spatial modulation MIMO systems. IEEE Communications Letters, 19(7):1145-1148, 2015.

[10] HUNG GANG, Y; LING, C ; HO MOW, W. Complex lattice reduction algorithm for low-complexity full-diversity mimo detection. IEEE Transactions on signal processing, 57(7), 2009. 
[11] GOLDEN, G; FOSCHINI, C; VALENZUELA, R ; WOLNIANSKY, P. Detection algorithm and initial laboratory results using v-blast space-time communication architecture. Electronics Letters, 35(1):14-16, 1999.

[12] ARÉVALO GARCIA, J. L. Interference Mitigation Schemes for the Uplink of Massive MIMO in 5G Heterogeneous Cellular Networks. 2016. $111 \mathrm{f}$. PhD thesis, Tese (Doutorado em Engenharia Eléctrica)Departamento de Engenharia Eléctrica, Pontificia Universidade Católica do Rio de Janeiro, Rio de Janeiro, 2016.

[13] SUNG, H; LEE, S ; LEE, I. Generalized channel inversion methods for multiuser mimo systems. IEEE Transactions on Communications, 57(11):3489-3499, 2009.

[14] JAKES, W. C. Microwave Mobile Communications. John Wiley and Sons Incorporation, 1974.

[15] PEREIRA, A; SAMPAIO-NETO, R. Low complexity soft-output mimo uplink detection for iterative detection and decoding systems. Journal of LaTeX Class Files, 14(8), 2015.

[16] BAKSALARY, J. K; BAKSALARY, O. M. "Particular formulae for the Moore-Penrose inverse of a columnwise partitioned matrix" Linear Algebra and its applications. Elsevier, 2006. 
A

\section{Equivalência entre os receptores ZF-ML e SVD-ML}

Considere um sistema MIMO multiusuário que obedece à modelagem apresentada no Capítulo 3. A expressão que relaciona os sinais transmitidos e que chegam ao receptor, apresentado em (3-6), é dado por:

$$
\mathbf{y}=\mathbf{H s}+\mathbf{n},
$$

onde $\mathbf{H}=\left[\begin{array}{llll}\mathbf{H}_{1} & \mathbf{H}_{2} & \ldots & \mathbf{H}_{N}\end{array}\right]$ é a matriz de canal, estruturada pelas submatrizes de canal $\mathbf{H}_{1}, \mathbf{H}_{2}, \ldots, \mathbf{H}_{N}$ referentes às classes de usuário $n=1,2, \ldots, N$ e $\mathbf{s}=\left[\begin{array}{llll}\mathbf{s}_{1}^{T} & \mathbf{s}_{2}^{T} & \ldots & \mathbf{s}_{N}^{T}\end{array}\right]^{T}$ o vetor de símbolos transmitidos pelos usuários $n=1,2, \ldots, N$.

Considere as duas estratégias de receptores consideradas, compostas pelos respectivos esquemas de desacoplamento seguido da detecção ótima da classe de usuários. Seja $\mathbf{A}_{n}=\mathbf{H}_{n}^{0}$ a matriz de desacoplamento ZF e $\mathbf{A}_{n}=\mathbf{U}_{0, n}$ a matriz de desacoplamento SVD.

Para o receptor baseado no desacoplador ZF, a detecção da classe $n$ é realizada por:

$$
\hat{\mathbf{s}}_{Z F}=\underset{\mathbf{s}_{n}}{\arg \min }\left(\mathbf{H}_{n}^{0} \mathbf{y}-\mathbf{s}_{n}\right)^{\mathcal{H}} \mathbf{K}_{n}^{-1}\left(\mathbf{H}_{n}^{0} \mathbf{y}-\mathbf{s}_{n}\right)
$$

$$
\begin{gathered}
\hat{\mathbf{s}}_{Z F}=\underset{\mathbf{s}_{n}}{\arg \min }\left(\mathbf{H}_{n}^{0} \mathbf{y}-\mathbf{s}_{n}\right)^{\mathcal{H}}\left(\mathbf{H}_{n}^{0} \mathbf{H}_{n}^{0^{\mathcal{H}}}\right)^{-1}\left(\mathbf{H}_{n}^{0} \mathbf{y}-\mathbf{s}_{n}\right) \\
\hat{\mathbf{s}}_{Z F}=\underset{\mathbf{s}_{\mathbf{n}}}{\arg \min }\left[\mathbf{y}^{\mathcal{H}} \mathbf{H}_{n}^{0^{\mathcal{H}}}\left(\mathbf{H}_{n}^{0} \mathbf{H}_{n}^{0^{\mathcal{H}}}\right)^{-1} \mathbf{H}_{n}^{0} \mathbf{y}-2 \operatorname{Re}\left(\mathbf{s}_{n}^{\mathcal{H}}\left(\mathbf{H}_{n}^{0} \mathbf{H}_{n}^{0^{\mathcal{H}}}\right)^{-1} \mathbf{H}_{n}^{0} \mathbf{y}\right)+\mathbf{s}_{n}^{\mathcal{H}}\left(\mathbf{H}_{n}^{0} \mathbf{H}_{n}^{0^{\mathcal{H}}}\right)^{-1} \mathbf{s}_{n}\right]
\end{gathered}
$$

Já para o receptor baseado no desacoplador SVD seguido do detector ótimo, a $n$-ésima classe é obtida fazendo-se:

$$
\hat{\mathbf{s}}_{S V D}=\underset{\mathbf{s}_{n}}{\arg \min }\left\|\mathbf{U}_{0, n}^{\mathcal{H}}\left(\mathbf{y}-\mathbf{H}_{n} \mathbf{s}_{n}\right)\right\|^{2}
$$




$$
\begin{gathered}
\hat{\mathbf{s}}_{S V D}=\underset{\mathbf{s}_{n}}{\arg \min }\left(\mathbf{U}_{0, n}^{\mathcal{H}} \mathbf{y}-\mathbf{U}_{0, n}^{\mathcal{H}} \mathbf{H}_{n} \mathbf{s}_{n}\right)^{\mathcal{H}}\left(\mathbf{U}_{0, n}^{\mathcal{H}} \mathbf{y}-\mathbf{U}_{0, n}^{\mathcal{H}} \mathbf{H}_{n} \mathbf{s}_{n}\right) \\
\hat{\mathbf{s}}_{S V D}=\underset{\mathbf{s}_{n}}{\arg \min }\left(\mathbf{y}^{\mathcal{H}} \mathbf{U}_{0, n} \mathbf{U}_{0, n}^{\mathcal{H}} \mathbf{y}-2 \operatorname{Re}\left\{\mathbf{s}_{n}^{\mathcal{H}} \mathbf{H}_{n}^{\mathcal{H}} \mathbf{U}_{0, n} \mathbf{U}_{0, n}^{\mathcal{H}} \mathbf{y}\right\}+\mathbf{s}_{n}^{\mathcal{H}} \mathbf{H}_{n}^{\mathcal{H}} \mathbf{U}_{0, n} \mathbf{U}_{0, n}^{\mathcal{H}} \mathbf{H}_{n} \mathbf{s}_{n}\right)
\end{gathered}
$$

Para as duas estratégias serem equivalentes, as expressões (A-4) e (A-7) devem ser idênticas.

Considere a matriz de canal particionada em colunas de acordo com as classes de usuários $\mathbf{H}=\left[\begin{array}{lll}\mathbf{H}_{1} & \mathbf{H}_{2} & \mathbf{H}_{N}\end{array}\right]$. Ademais, seja $\mathbf{Q}_{n}$ a matriz projetora no espaço vetorial ortogonal a $\mathbf{H}_{n}$. Segundo [16], a pseudoinversa de $\mathbf{H}$, denotada por $\mathbf{H}^{\dagger}$, pode ser representada por:

$$
\mathbf{H}^{\dagger}=\left[\begin{array}{llll}
\mathbf{H}_{1}^{0} & \mathbf{H}_{2}^{0} & \ldots & \mathbf{H}_{N}^{0}
\end{array}\right]^{T}=\left[\begin{array}{llll}
\left(\mathbf{Q}_{1} \mathbf{H}_{1}\right)^{\dagger} & \left(\mathbf{Q}_{2} \mathbf{H}_{2}\right)^{\dagger} \ldots\left(\mathbf{Q}_{N} \mathbf{H}_{N}\right)^{\dagger}
\end{array}\right]^{T}
$$

A matriz $\mathbf{H}_{n}^{0}$, de tamanho $M_{t_{n}} \times N_{r}$, é a que desacopla a $n$-ésima classe de usuários. A matriz projetora pode ser expressa em função da matriz unitária $\mathbf{Q}_{n}=\mathbf{U}_{0, n} \mathbf{U}_{0, n}^{\mathcal{H}}$. Assim, $\mathbf{H}_{n}^{0}$ é desenvolvida fazendo-se:

$$
\mathbf{H}_{n}^{0}=\left(\mathbf{Q}_{n} \mathbf{H}_{n}\right)^{\dagger}=\left(\mathbf{U}_{0, n} \mathbf{U}_{0, n}^{\mathcal{H}} \mathbf{H}_{n}\right)^{\dagger}
$$

$$
\mathbf{H}_{n}^{0}=\left(\mathbf{H}_{n}^{\mathcal{H}} \mathbf{U}_{0, n} \mathbf{U}_{0, n}^{\mathcal{H}} \mathbf{H}_{n}\right)^{-1} \mathbf{H}_{n}^{\mathcal{H}} \mathbf{U}_{0, n} \mathbf{U}_{0, n}^{\mathcal{H}}
$$

Na expressão (A-4), apenas os dois últimos termos da minimização são função do vetor de símbolos $\mathbf{s}_{n} \mathrm{e}, \operatorname{logo}$, relevantes para avaliar a equivalência das estratégias. Desenvolvendo estes termos em (A-4), temos:

$$
\begin{array}{r}
-2 \operatorname{Re}\left[\mathbf{s}_{n}^{\mathcal{H}}\left(\mathbf{H}_{n}^{0^{\mathcal{H}}} \mathbf{U}_{0, n} \mathbf{U}_{0, n}^{\mathcal{H}} \mathbf{H}_{n}^{0}\right)\left(\mathbf{H}_{n}^{0^{\mathcal{H}}} \mathbf{U}_{0, n} \mathbf{U}_{0, n}^{\mathcal{H}} \mathbf{H}_{n}^{0}\right)^{-1} \mathbf{H}_{n}^{0^{\mathcal{H}}} \mathbf{U}_{0, n} \mathbf{U}_{0, n}^{\mathcal{H}} \mathbf{y}\right] \\
+\mathbf{s}_{n}^{\mathcal{H}}\left(\mathbf{H}_{n}^{0^{\mathcal{H}}} \mathbf{U}_{0, n} \mathbf{U}_{0, n}^{\mathcal{H}} \mathbf{H}_{n}^{0}\right) \mathbf{s}_{n} \\
=-2 \operatorname{Re}\left[\mathbf{s}_{n}^{\mathcal{H}} \mathbf{H}_{n}^{0^{\mathcal{H}}} \mathbf{U}_{0, n} \mathbf{U}_{0, n}^{\mathcal{H}} \mathbf{y}\right]+ \\
+\mathbf{s}_{n}^{\mathcal{H}}\left(\mathbf{H}_{n}^{0^{\mathcal{H}}} \mathbf{U}_{0, n} \mathbf{U}_{0, n}^{\mathcal{H}} \mathbf{H}_{n}^{0}\right) \mathbf{s}_{n} .
\end{array}
$$


A expressão acima é igual aos termos dependentes de $\mathbf{s}_{n}$ no argumento de (A-7). Isto prova a equivalência entre os receptores ZF-ML e SVD-ML. 